\title{
Homeostatic Dysregulation in Membrane Properties of Masticatory Motoneurons Compared with Oculomotor Neurons in a Mouse Model for Amyotrophic Lateral Sclerosis
}

\author{
Sharmila Venugopal, ${ }^{1}$ Chie-Fang Hsiao, ${ }^{1}$ Takuma Sonoda, ${ }^{1}{ }^{\oplus}$ Martina Wiedau-Pazos, ${ }^{2}$ and Scott H. Chandler ${ }^{1}$ \\ ${ }^{1}$ Departments of Integrative Biology and Physiology, and ${ }^{2}$ Neurology, David Geffen School of Medicine, University of California at Los Angeles, Los Angeles, \\ California 90095
}

\begin{abstract}
Amyotrophic lateral sclerosis (ALS) is a progressive neurodegenerative motoneuron disease with presently no cure. Motoneuron (MN) hyperexcitability is commonly observed in ALS and is suggested to be a precursor for excitotoxic cell death. However, it is unknown whether hyperexcitability also occurs in MNs that are resistant to degeneration. Second, it is unclear whether all the MNs within homogeneous motor pools would present similar susceptibility to excitability changes since high-threshold MNs innervating fast fatigable muscle fibers selectively degenerate compared with low-threshold MNs innervating fatigue resistant slow muscle fibers. Therefore, we concurrently examined the excitability of ALS-vulnerable trigeminal motoneurons (TMNs) controlling jaw musculature and ALSresistant oculomotor neurons (OMNs) controlling eye musculature in a well studied SOD1 ${ }^{\mathrm{G} 93 \mathrm{~A}}$ ALS mouse model using in vitro patchclamp electrophysiology at presymptomatic ages P8-P12. Our results show that hyperexcitability is not a global change among all the MNs, although mutant SOD1 is ubiquitously expressed. Instead, complex changes occur in ALS-vulnerable TMNs based on motor unit type and discharge characteristics. Firing threshold decreases among high-threshold TMNs and increases in a subpopulation of lowthreshold TMNs. The latter group was identified based on their linear frequency-current responses to triangular ramp current injections. Such complex changes in MN recruitment were absent in ALS-resistant OMNs. We simulated the observed complex changes in TMN excitability using a computer-based jaw closer motor pool model. Model results suggest that hypoexcitability may indeed represent emerging disease symptomology that causes resistance in muscle force initiation. Identifying the cellular and molecular properties of these hypoexcitable cells may guide effective therapeutic strategies in ALS.
\end{abstract}

Key words: brainstem; excitability; mastication; neurodegeneration; presymtomatic

\section{Introduction}

Amyotrophic lateral sclerosis (ALS) is a devastating disease involving degeneration of brain and spinal MNs leading to muscle atrophy, paralysis, and death (Bruijn et al., 2004). Transgenic mouse models of the human neurodegenerative motoneuron disease, ALS mimic the progressive loss of motoneurons (MNs) and allow investigation of mechanisms underlying disease vulnerability. Motoneuron axons die-back causing muscle denervation and loss of functional motor units before MN loss and overt symptoms (Kanning et al., 2010). Moreover, motor axons of fast fatigable (FF) MUs are the first to retract presymptomatically followed by the fast-fatigue resistant (FR) MUs, whereas the slow

\footnotetext{
Received April 25, 2014; revised 0ct. 12, 2014; accepted 0ct. 17, 2014.

Author contributions: S.V. and S.H.C. designed research; S.V. and C.-F.H. performed research; M.W.-P. contributed unpublished reagents/analytic tools; S.V., C.-F.H., T.S., and S.H.C. analyzed data; S.V. and S.H.C. wrote the paper.

This work was supported by Grant NS071348 to S.H.C. We thank Dr Dwayne Simmons' laboratory for the confocal imaging facility, and Kelly Lucchesi for assisting with mouse genotyping.

The authors declare no competing financial interests.

Correspondence should be addressed to Dr Scott H. Chandler, UCLA, 2859 Slichter Hall, 603 Charles East Young Drive East, Los Angeles, CA 90095-7246. E-mail: schandler@physci.ucla.edu.

DOI:10.1523/JNEUROSCI.1682-14.2015

Copyright $\odot 2015$ the authors $\quad 0270-6474 / 15 / 350707-14 \$ 15.00 / 0$
}

(S) MUs are spared until the end stage (Pun et al., 2006). Motoneurons forming the FF MUs typically are larger cells with higher recruitment threshold and lower-input resistance than the fatigue resistant (FR and S) MUs (Kernell, 1966; Burke, 1981). This well known "size principle" is fundamental to the "recruitment order" of motor units of a muscle wherein smaller, low-threshold MUs are recruited first followed by larger higherthreshold MUs resulting in increasing muscle force (Enoka and Pearson, 2013). The observed differential MU (Hegedus et al., 2007) and axonal vulnerability (Pun et al., 2006) in ALS raises the possibility of differential abnormalities in MNs forming fast versus slow MUs. Although membrane hyperexcitability has been reported among prototypical MNs (Pieri et al., 2003; Kuo et al., 2004; Durand et al., 2006; van Zundert et al., 2008; Quinlan et al., 2011), whether this occurs regardless of motor unit size is unknown. Concomitant with the preferential loss of fast MUs, an activity-dependent conversion to fatigue resistant MUs occurs that may increase resilience and survival (Hegedus et al., 2008; Gordon et al., 2010). It is unknown whether compensatory changes occur in MN excitability, and if so, how this would alter muscle function. Additionally, a motor pool can consist of MNs with heterogeneous discharge properties (Cotel et al., 2009) that are altered in various diseases (Bennett et al., 2001b; Bories et al., 
2007). Therefore, we hypothesized that ALS vulnerable MNs show presymptomatic abnormalities in membrane properties that may be selective to MU type and MN discharge characteristics.

Second, it is unknown whether the ubiquitous expression of mutant SOD1 alters MN excitability in disease resistant motor nuclei, such as the brainstem oculomotor neurons. The oculomotor neurons (OMNs) and the related oculomotor functions are relatively spared in ALS patients (Radcliffe and Lockhart Clarke, 1862) and in mouse models of the disease (Nimchinsky et al., 2000; Angenstein et al., 2004; Niessen et al., 2006). In contrast, the closely located brainstem trigeminal motoneurons controlling jaw movements are vulnerable to degeneration (Angenstein et al., 2004; Niessen et al., 2006; Ferrucci et al., 2010) and the related masticatory functions are compromised to varying degrees in ALS (Brooks, 1996). The mechanisms underlying the early changes in neuronal excitability, whether causative or adaptive, are not clear. Early homeostatic and compensatory regulation for neuroprotection of the motor pool undoubtedly masks early disease deficits (Saxena et al., 2013). Here we focus on the early adaptive changes in excitability in ALS-vulnerable trigeminal motoneurons (TMNs) and ALS-resistant OMNs in a postnatal (P8-P12) SOD1 ${ }^{\text {G93A }}$ ALS mouse model (Gurney et al., 1994) to gain insight into the mechanisms underlying disease progression and the basis for differential vulnerability of neuron types.

\section{Materials and Methods}

Transgenic mice overexpressing the human SOD1 ${ }^{\mathrm{G} 93 \mathrm{~A}}$ transgene and their WT littermates were used for this study. Experiments were performed on postnatal 8- to 12-d-old mice of either sex. Data presented are from 113 motoneurons with 60 cells from $42 \mathrm{WT}$ animals and 53 cells from 38 age-matched SOD1 ${ }^{\text {G93A }}$ high expressor mutant animals. All animal protocols were approved by the Institutional Animal Care and Use Committee at UCLA.

Motoneuron identification. The trigeminal motor nucleus was identified in coronal brainstem slices in bright field as an opaque, pale oval region that is medial to the trigeminal principal sensory nucleus and ventrolateral to the periaqueductal gray (Chandler et al., 1994). Of the 75 TMNs presented in this study, 46 were labeled with a red fluorescent dye (AlexaFluor 568 hydrazide) injected from the pipette during patch-clamp recording for post hoc imaging and location analyses. In some instances $(26 / 75$ cells), the TMNs were identified in retrogradely labeled motor trigeminal nucleus (Mot V) by injecting a green fluorescent retrograde tracer (AlexaFluor 488 hydrazide)

\section{A Retrogradely labeled jaw closer TMNs}
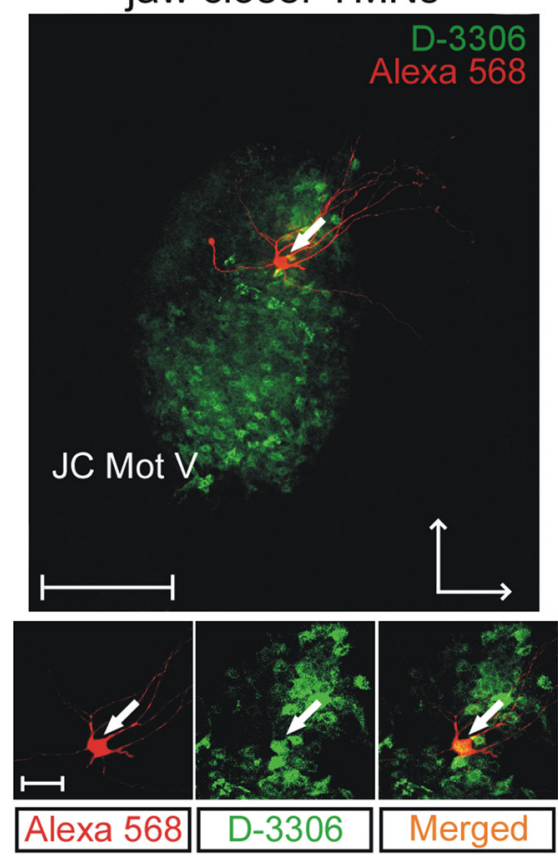

B

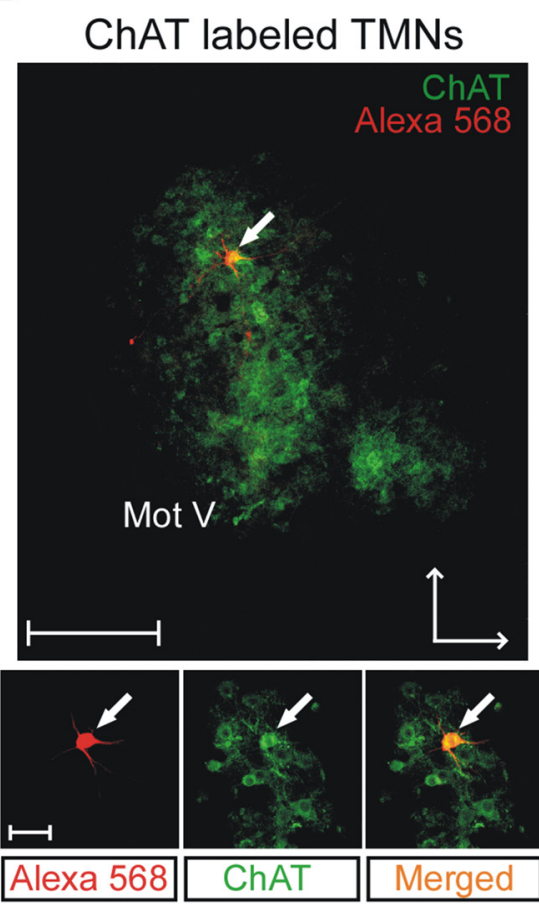

\section{ChAT labeled OMNs}



Figure 1. Identification of trigeminal and oculomotor motoneurons. $\boldsymbol{A}$, Top, Trigeminal motor nucleus labeled by retrograde tracer injection into JC muscles; D-3306: green fluorescent dextran injected into the JC muscles shows labeled cell bodies of JC TMNs; AlexaFluor 568: red fluorescent dye filled single motoneuron. Bottom, High-magnification image of the double-labeled JC TMN with D-3306 and AlexaFluor 568. B, Top, Trigeminal motor nucleus (Mot V) immunolabeled for ChAT using AlexaFluor 488 (green). The ventromedial cell group is also seen; Alexa Fluor 568: red fluorescent dye placed in the patch pipette filled the MN during patch-clamp recording, in turn double-labeling the TMN in the dorsolateral aspect of the Mot $V$ where jaw closers are present. Bottom, High-magnification image of the double-labeled TMNs with AlexaFluor 488 (ChAT) and AlexaFluor 568 in the cell. C, Top, Oculomotor nucleus bilaterally identified by ChAT immunohistochemistry using AlexaFluor 488 (green). AlexaFluor 568 fill of a ChAT-positive 0MN (red). Aq, Cerebral aqueduct; mid, midline. Bottom, High-magnification image of the double-labeled OMN with AlexaFluor 488 (ChAT) and AlexaFluor 568 in the cell. Scale bars: low-magnification, $200 \mu \mathrm{m}$; high-magnificatio, $40 \mu \mathrm{m}$. $\boldsymbol{A}, \boldsymbol{B}$, Horizontal arrows indicate medial and vertical arrows indicate dorsal orientations. 
A

WT

$\operatorname{SOD} 1^{\text {G93A }}$

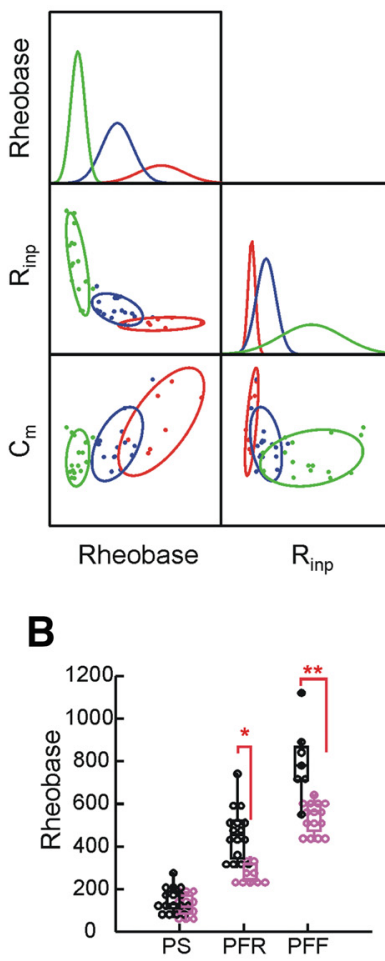

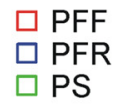

$\mathrm{C}_{\mathrm{m}}$

aWT
Rheobase

$\square \operatorname{SOD} 1^{\mathrm{G} 93 \mathrm{~A}}$

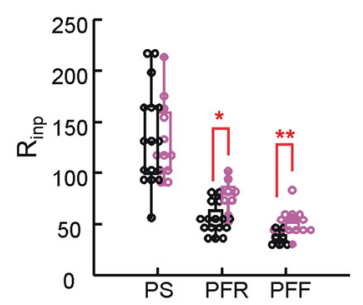

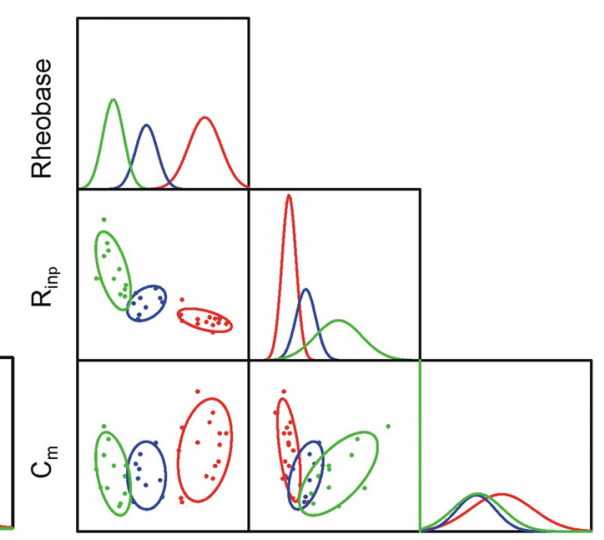

$\mathrm{C}_{\mathrm{m}}$

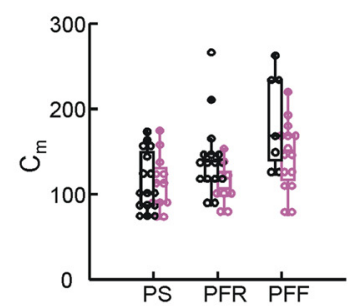

\section{C}
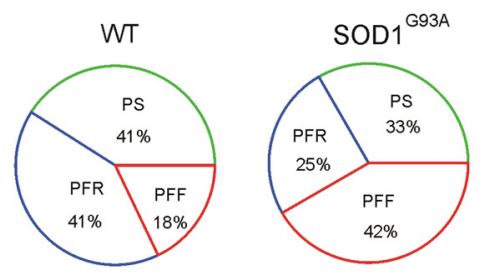

D



Figure 2. Motor unit classification based on TMN membrane properties. $\boldsymbol{A}$, Scatterplot matrices of membrane properties including rheobase, $R_{\text {inp }}$ and $C_{\mathrm{m}}$ showing the result of $k$-means clustering based classification of motor units with PS in green, PFR in blue, and PFF in red, in both WT (left) and SOD1 ${ }^{\text {G93A }}$ (right) TMNs. The diagonal cells show the normal curves for each MU group. In WT the $F$-ratios were 130.2, 26.4, and 12.9, and in the mutant these values were 163.2, 36.6, and 3.7, respectively, for rheobase, input resistance, and membrane capacitance. $\boldsymbol{B}$, Comparison of membrane properties of MU groups between WT (black) and

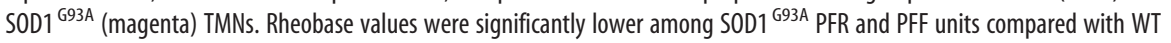
(Student's $t$ test, ${ }^{*} p=0.0002$ for PFR, ${ }^{* *} p=0.0001$ for PFF), whereas $R_{\text {inp }}$ values were significantly greater (Student's $t$ test, ${ }^{*} p=$ 0.0009 for PFR, ${ }^{* *} p=0.0028$ for PFF). Error bars indicate SD. $\boldsymbol{A}, \boldsymbol{B}$, Units of rheobase, $R_{\text {inp }}$, and $C_{\mathrm{m}}$ are $\mathrm{pA}, \mathrm{M} \Omega$, and $\mathrm{pF}$, respectively. $C$, Chi-square test of distribution of the three MU types in WT and S0D1 ${ }^{\mathrm{G} 93 \mathrm{~A}}$ Mot V yielded significant difference $(p=0.0014)$ for the presented dataset. $\boldsymbol{D}$, Distribution of cells across the age range considered (P8 -P12). Data from 28 WT mice $(n=39)$ and 26 SOD1 ${ }^{\text {G93A }}$ mutant mice $(n=36)$, where $n$ is the number of cells.

into the jaw closer (JC) musculature $48-72 \mathrm{~h}$ before patch-clamp recording (Fig. 1A). Fifteen TMNs with the red dye were identified in the Mot $\mathrm{V}$ using post hoc confocal imaging of which nine cases were used for doublelabeling with choline acetyl transferase (ChAT) with green AlexaFluor 488 hydrazide to further affirm motoneuron identity (Fig. 1B). In initial experiments, the location of the oculomotor nucleus (Mot III) was confirmed in the ventrolateral corner of the periaqueductal gray by retrogradely labeling the Mot III by injection of a green retrograde tracer (AlexaFluor 488 hydrazide) into the extraocular musculature $48-72 \mathrm{~h}$ before slice preparation. The located Mot III sections were $1 \mathrm{~mm}$ rostral from the sections containing the trigeminal motor nucleus. In subsequent experiments without retrograde tracing of the Mot III nucleus, patched OMN location was confirmed by injecting a red fluorescent dye (AlexaFluor 568 hydrazide) into the cell during patch-clamp recording followed by post hoc confocal imaging of the cell location in 20/38 cells. In a subset of these cells (5/20), motoneuron identity was further affirmed by double-labeling with ChAT (green AlexaFluor 488 hydrazide) immunohistochemistry (Fig. 1C).

Solutions. All solutions were bubbled with $95 \% \mathrm{O}_{2} / 5 \% \mathrm{CO}_{2}$ and maintained at $\mathrm{pH} 7.25-$ 7.3. The brain-cutting solution used during slice preparation was composed of the following (in mM): $126 \mathrm{NaCl}, 3 \mathrm{KCl}, 1.25 \mathrm{NaH}_{2} \mathrm{PO}_{4}$, $26 \mathrm{NaHCO}_{3}, 10$ glucose, $1 \mathrm{CaCl}_{2}, 5 \mathrm{MgCl}_{2}$, and 4 lactic acid (Del Negro and Chandler, 1998; del Negro et al., 1999), or $85 \mathrm{NaCl}, 2.5 \mathrm{KCl}$, $1.25 \mathrm{NaH}_{2} \mathrm{PO}_{4}, 24 \mathrm{NaHCO}_{3}, 25$ glucose, $75 \mathrm{su}$ crose, $0.5 \mathrm{CaCl}_{2}$, and $4 \mathrm{MgCl}_{2}$ (Gupta et al., 2012). The slice incubation solution was composed of the following (in $\mathrm{mm}$ ): $124 \mathrm{NaCl}, 3$ $\mathrm{KCl}, 1.25 \mathrm{NaH}_{2} \mathrm{PO}_{4}, 26 \mathrm{NaHCO}_{3}, 10$ glucose, 2 $\mathrm{CaCl}_{2}, 2 \mathrm{MgCl}_{2}$, and 4 lactic acid (Schurr et al., 1988). The external recording solution during patch-clamp recording consisted of the following (in mM): $124 \mathrm{NaCl}, 3 \mathrm{KCl}, 1.25 \mathrm{NaH}_{2} \mathrm{PO}_{4}$, $26 \mathrm{NaHCO}_{3}, 10$ glucose, $2 \mathrm{CaCl}_{2}$, and $2 \mathrm{MgCl}_{2}$. The pipette internal solution used in currentclamp experiments was composed of the following (in $\mathrm{mm}$ ): $115 \mathrm{~K}$-gluconate, $9 \mathrm{NaCl}$, $1 \mathrm{MgCl}_{2}, 10$ HEPES buffer, 0.2 EGTA, $3 \mathrm{~K} 2-$ ATP, and $1 \mathrm{Na}-\mathrm{GTP}$ with a $\mathrm{pH}$ between 7.28 and 7.3, and osmolarity between $290 \pm 5$ mOsm.

Slice preparation. $\mathrm{P} 8-\mathrm{P} 12$ mice were anesthetized by inhalation of isofluorane and then decapitated. The brain was then removed and immersed in ice-cold cutting solution. The extracted brain block was mounted on a vibrating slicer (DSK Microslicer, Ted Pella) supported by an agar block. Coronal brainstem sections $(250 \mu \mathrm{m})$ consisting of Mot V and Mot III were obtained from caudal to rostral order. Slices were then placed into the incubation solution for $40-50 \mathrm{~min}$ at room temperature $\left(22-24^{\circ} \mathrm{C}\right)$.

Patch-clamp electrophysiology. Patch pipettes (3-5 M $\Omega$ ) were pulled using a Brown/Flaming P-97 micropipette puller (Sutter Instruments). Slices were perfused with oxygenated recording solution ( $2 \mathrm{ml} / \mathrm{min}$ ) while secured in a glass bottom recording chamber mounted on a Zeiss fixed-stage Axioskop microscope. Neurons were visualized with infrared differential video microscopy. Current-clamp recordings were performed with an Axopatch-1D amplifier (Molecular Devices) with pCLAMP acquisition software (v9.2, Medical Devices) with a sampling rate between 20 and $50 \mathrm{kHz}$. Signals were grounded by a $3 \mathrm{M} \mathrm{KCl}$ agar bridge electrode mounted in the recording well.

Data analysis and statistics. Data were analyzed using Clampfit v9.2 (Molecular Devices), Sigma-Aldrich Plot v9.0, SYSTAT 13 (Systat Software), StatView (SAS Institute), and Microsoft Excel. Cells with resting membrane potential more negative than $-50 \mathrm{mV}$ and action potential height $\geq 70 \mathrm{mV}$ measured from spike voltage threshold to peak amplitude were included in the dataset. Although interneurons were avoided during patch-clamp recording through selection of visibly large neurons when retrograde tracer was not used, acceptable motoneurons had membrane capacitance $>70$ and $<300 \mathrm{pF}$ and input resistance $<200 \mathrm{M} \Omega$ in agreement with values noted from our identified motoneuron recordings. One of two protocols was used to measure membrane capacitance: (1) $15 \mathrm{~ms}$ hyperpolarizing voltage commands from -70 to $-50 \mathrm{mV}$ in 5 $\mathrm{mV}$ steps, and, (2) 10 sweeps of $10 \mathrm{~ms}$ voltage command from -70 to $-50 \mathrm{mV}$. In both cases, membrane capacitance was calculated as the 
average of the integral of capacitive current across the voltage sweeps. Input resistance was determined from the slope of the linear portion of the steady-state $I-V$ relationship from a -60 $\mathrm{mV}$ holding potential in current-clamp mode. Voltage responses at the end of $1 \mathrm{~s}$ hyperpolarizing current pulses were used to obtain the $I-V$ relationship. Steady-state mean frequencies in response to $1 \mathrm{~s}$ current pulses were obtained by calculating the mean frequency of the last 500 $\mathrm{ms}$ of the evoked action potential train. Discharge patterns of cells were classified based on membrane response to triangular ramp current injection of $10 \mathrm{~s}$ duration and magnitude between 1.5 and 5 times firing threshold current. Instantaneous firing frequencies were calculated to generate $f-I$ curves. The results are reported as mean $\pm \mathrm{SD}$, unless stated otherwise. Statistical tests consisted of Student's $t$ test, two-way repeated-measures ANOVA and $\chi^{2}$ proportionality test, and group differences were considered significant if $p<0.05$.

Motor unit prediction based on MN membrane properties. We predicted motor unit type as slow and fast (fatigable or fatigue resistant) based on membrane properties of motoneurons recorded in this study. Previous studies have demonstrated that mechanically typed spinal MUs can be classified into fast (FF, FR) and slow based on membrane properties, such as rheobase and input resistance of the motoneurons with $>90 \%$ accuracy (Zengel et al., 1985). Because such measurements are com-

monly made during patch-clamp recordings, we used predictive $k$-means clustering algorithm (SYSTAT 13) to classify motor unit types based on rheobase, input resistance, and membrane capacitance of motoneurons as categorical variables. The algorithm is based on iterative assignment of a set of observations into $k$-clusters by maximizing between-cluster variation and minimizing within-cluster variation. Squared Euclidean distance from the cluster mean was chosen as the parameter that determines cluster variations. Initial seeds ( $k$ mean values) were not explicitly specified since the observations were made independent of any associable mechanical properties traditionally used for motor unit typing and hence initial cluster means could not be assumed. Significance of classification was noted by the F-ratio (ratio of between group variance and within group variance) for each categorical variable. Larger $F$-ratio denoted better statistical power of the categorical variable in distinguishing the underlying clusters in the dataset.

Immunohistochemistry and confocal imaging. AlexaFluor 568 fluorescent dye in the pipette internal solution filled the cells during whole-cell patch-clamp recording. Slices obtained after recording were placed in a $2 \%$ paraformaldehyde $\mathrm{PBS}$ solution overnight at $4^{\circ} \mathrm{C}$, and then permeabilized in 2\% Triton X-100 to increase antibody penetration. Motoneuron identity was confirmed by incubating sections in primary goat antibody against ChAT (1:500). Slices were then incubated in Northern Lights 493 donkey anti-goat secondary antibody (1:200; R\&D Systems) and mounted on glass slides (Fisher) using aqueous mounting medium (Daido-Sangyo). Slices were then imaged using a confocal microscope (Zeiss LSM 5) attached to an upright microscope (Zeiss, AxioImager) along with Zen 2008 software (Carl Zeiss MicroImaging). Motoneuron identity was confirmed when the cell that was filled with red dye was double-labeled with green ChAT immunolabeling in the nucleus of interest (Fig. 1). For morphology analyses, $z$-stack images were obtained at high-magnification $(63 \times)$ with $1 \mu \mathrm{m}$ depth resolution. Three-dimensional projection of cells were rendered from $z$-stacks using Volocity 3D Image Analysis software (PerkinElmer) and a region-of-interest was manually established to measure soma surface area excluding dendrites.

Genotyping. Mouse genotype as homozygous WT or heterozygous SOD $1^{\text {G93A }}$ was determined using standard PCR technique using the
DNeasy 96 Blood and Tissue Kit (Qiagen) according to the manufacturer's protocols. Briefly, frozen samples (mouse tails $\sim 0.5 \mathrm{~cm}$ ) were incubated overnight $(16-18 \mathrm{~h}$ ) in $0.2 \mathrm{ml}$ lysis buffer (80\% ATL and $20 \%$ proteinase K, DNeasy Kit) at $56^{\circ} \mathrm{C} .200 \mu \mathrm{l} \mathrm{AL}$ buffer and $200 \mu \mathrm{l} 100 \%$ ethanol were added to the lysate before loading onto the DNeasy Mini Spin Column and centrifuged at $6000 \mathrm{rpm}$ for $1 \mathrm{~min}$ to allow selective DNA binding to DNeasy membrane. This was followed by two efficient wash steps to remove remaining contaminants and enzyme inhibitors. The supernatant was incubated in AE buffer for $1 \mathrm{~min}$ and then centrifuged. The collected sample was used for PCR. The PCR mix for each sample consisted of $10 \mu \mathrm{l} 2 \times$ TAG PCR Master Mix, four primers, $0.5 \mu \mathrm{l}$ each for PCR amplification, $6 \mu \mathrm{l}$ of double-distilled water and $2 \mu \mathrm{l}$ of DNA from sample. PCR amplification used the following primers $\left(5^{\prime}\right.$ to $3^{\prime}$ ): for the wild-type allele, CTAGGCCACAGAATTGAAAGATCT and GTAGGTGGAAATTCTAGCATCATCC; and for the mutant allele, CATCAGCCCTAATCCATCTGA and CGCGACTAACAATCAAAG TGA (Integrated DNA Technologies). The reaction consisted of $3 \mathrm{~min}$ at $94^{\circ} \mathrm{C}, 35$ cycles of $30 \mathrm{~s}$ at $95^{\circ}, 30 \mathrm{~s}$ at $60^{\circ} \mathrm{C}, 45 \mathrm{~s}$ at $72^{\circ} \mathrm{C}$, and $2 \mathrm{~min}$ at $72^{\circ} \mathrm{C}$. PCR products were separated on a $1.5 \%$ agarose gel, allowing resolution of a $324 \mathrm{bp}$ product for the WT allele and a $236 \mathrm{bp}$ product for the mutant allele.

Motor pool simulation model. Identifying a single motor pool using retrograde tracer injection is technically challenging in neonates. Nonetheless, our retrograde tracer injection targeted musculature visibly located on either sides of the jaw laterally in the mandibular region (thus excluding jaw openers) that labeled one or more JC motor pools: masseter, temporalis, and pterygoid. All the post hoc identified TMNs were in the lateral aspect of the Mot V corresponding to the dorsolateral subdivisions of the trigeminal motor nucleus consisting of JC motor pools (Limwongse and DeSantis, 1977; Matsuda et al., 1978; Uemura-Sumi et al., 1982). Therefore, we assumed a motor pool consisting of JC MNs for our model simulation. Classical studies suggest that based on the muscle fiber type composition, all the jaw closer muscles are considered fast muscles (Taylor et al., 1973). Particularly in the rat (Hiiemae, 1971), as well as in the mouse (Gojo et al., 2002), 70\% of the fibers types in all of the above three jaw closer muscles are FF, whereas the remaining 
Table 1. Membrane properties of WT and SOD $1{ }^{\text {G93A }}$ TMNs classified by predicted MU type

\begin{tabular}{|c|c|c|c|c|c|c|}
\hline \multirow[b]{2}{*}{ Membrane property } & \multicolumn{2}{|l|}{ PS } & \multicolumn{2}{|l|}{ PFR } & \multicolumn{2}{|l|}{ PFF } \\
\hline & WT $(n=16)$ & $\mathrm{SOD1}^{\mathrm{G}}{ }^{\mathrm{GPA}}(n=12)$ & $\overline{\mathrm{WT}}(n=16)$ & $\operatorname{SOD1}{ }^{\mathrm{G} 93 \mathrm{~A}}(n=9)$ & $\overline{\mathrm{WT}}(n=16)$ & $\mathrm{SOD}^{\mathrm{G}}{ }^{\mathrm{G} 93 \mathrm{~A}}(n=15)$ \\
\hline$C_{m}, p F$ & $115.0 \pm 8.4$ & $114.0 \pm 7.8$ & $142.2 \pm 11.0$ & $111.7 \pm 8.3$ & $185.6 \pm 21.2$ & $144.7 \pm 10.5$ \\
\hline$R_{\text {inp }}, \mathrm{M} \Omega$ & $132.8 \pm 12.8$ & $131.7 \pm 8.4$ & $59.1 \pm 3.9$ & $78.6 \pm 5.3^{*}$ & $35.7 \pm 2.2$ & $51.4 \pm 3.0^{* *}$ \\
\hline RMP, mV & $-61.6 \pm 1.8$ & $-60.1 \pm 1.6$ & $-65.5 \pm 1.2$ & $-65.9 \pm 2.4$ & $-67.4 \pm 1.6$ & $-64.4 \pm 1.5$ \\
\hline Rheobase, pA & $151.6 \pm 13.8$ & $123.8 \pm 13.8$ & $459.1 \pm 30.2$ & $274.4 \pm 16.5 \dagger$ & $800.7 \pm 67.3$ & $539.3 \pm 19.1+\dagger$ \\
\hline AP threshold, $\mathrm{mV}$ & $-40.0 \pm 1.3$ & $-39.4 \pm 1.2$ & $-33.5 \pm 1.3$ & $-36.5 \pm 2.6$ & $-33.5 \pm 2.3$ & $-31.2 \pm 1.3$ \\
\hline AP height, $\mathrm{mV}$ & $83.5 \pm 2.8$ & $85.7 \pm 2.8$ & $79.1 \pm 2.2$ & $83.3 \pm 3.7$ & $82.1 \pm 2.6$ & $73.8 \pm 1.5 \ddagger$ \\
\hline AP half-width, ms & $1.0 \pm 0.05$ & $0.9 \pm 0.1$ & $0.8 \pm 0.04$ & $1.0 \pm 0.1 \#$ & $0.7 \pm 0.07$ & $0.8 \pm 0.0$ \\
\hline AHP, mV & $-5.4 \pm 1.3$ & $-3.8 \pm 1.1$ & $-4.0 \pm 1.1$ & $-5.4 \pm 1.5$ & $-3.4 \pm 1.1$ & $-3.4 \pm 0.7$ \\
\hline
\end{tabular}

Values reported as mean \pm SEM. Student $t$ tests were performed for statistical comparison between WT and SOD1 ${ }^{\mathrm{G} 93 \mathrm{~A}}$ neurons within the three predicted MU types. Symbols indicate statistical significance, where: ${ }^{*} p=0.007$, ${ }^{* *} p=0.003, \dagger p=0.00024, \mathrm{t} p=7.83712 \mathrm{E}-05, \neq p=0.0074, \# p=0.032$. Bold face highlights values that show statistical significance in the mutant.

$(\sim 30 \%)$ represent slow-twitch and FR types. Hence, we assumed a motor pool consisting of $100 \mathrm{MNs}$ of which 70 were MNs corresponding to fast MUs and 30 were MNs corresponding to slow MUs. Each MN was represented by three sets of intrinsic properties: (1) the steady-state frequency-current $(f-I)$ gain functions $G_{1}$ (gain in the primary range) and $G_{2}$ (gain in the secondary range; Granit et al., 1966), (2) threshold currents for recruitment $\left(I_{\text {thresh }}\right)$ and primary-to-secondary range transition current $\left(I_{\text {trans }}\right)$, and $(3)$ recruitment frequency $\left(f_{\text {thresh }}\right)$ and transition frequency from $G_{1}$ to $G_{2}\left(f_{\text {thresh }}\right)$. All of these values were derived from our present data. Table 3 shows the distribution of these properties for the entire motor pool along with the assumed properties of the muscle. The two main sets of MN properties that were explicitly altered to simulate abnormalities in SOD $1{ }^{\text {G93A }}$ TMNs include the cells' recruitment threshold $\left(I_{\text {thresh }}\right)$, and $f-I$ gain values $\left(\mathrm{G}_{1}\right.$ and $\left.\mathrm{G}_{2}\right)$. Changes in $I_{\text {thresh }}$ in turn altered $I_{\text {trans }}$ as given by the following equation:

$$
I_{\text {trans }}=I_{\text {thresh }}+\left(\frac{f_{\text {trans }}-f_{\text {thresh }}}{G_{1}}\right)
$$

(see Results).

The isometric MU force-frequency transformation was performed as by Heckman and Binder (1991) based on the following equation:

$$
F=F_{\max }\left(1-e^{\left(\left(\frac{f}{T_{f}}\right)^{p}\right)}\right) .
$$

$F_{\text {max }}$ is the maximal tetanic force of the MU, and its range across the 100 MUs was based on the range of isometric contraction forces achieved at the optimal jaw muscle length reported in rabbit masseter muscle units (Turkawski and van Eijden, 2000; van Eijden and Turkawski, 2002) due to lack of more specific data from mice. $T_{f}$ is a frequency constant related to the speed of contraction of the muscle unit and was estimated using the following equation:

$$
T_{f}=\frac{f_{\text {thresh }}}{(0.0834)^{p}}
$$

where

$$
P=\frac{1}{\log _{19.3}\left(\frac{f_{\text {trans }}}{f_{\text {thresh }}}\right)},
$$

a factor that transforms an exponential to sigmoid function. The above MU force-frequency functions were based on the percentages of maximal force output actually generated by motor units at $f_{\text {thresh }}$ and $f_{\text {trans }}$, assuming nearly $8 \%$ of $F_{\max }$ is generated at $f_{\text {thresh }}$ and $80 \%$ of $F_{\max }$ is generated at $f_{\text {trans }}$ (i.e., at the end of the primary range; Kernell, 1979). The steady-state input-output function of the simulated motor pool (i.e., isometric force versus effective $\mathrm{MN}$ pool input) is a sigmoidal curve where each value on the curve is a summation of all of the MU forces at that input level (Kernell et al., 1983); i.e.,

$$
F_{\text {isometric }}=\sum_{i=1}^{100} F_{i}
$$

where $F_{i}$ is the isometric MU force obtained above. Note that the properties of muscle fibers were not modeled explicitly and were assumed not to change significantly at this postnatal stage in the mutant mouse. The motor pool model was constructed and simulated using MATLAB (MathWorks).

\section{Results}

Prediction of motor unit types and hyperexcitable shifts in SOD1 ${ }^{\text {G93A }}$ TMNs forming fast motor units

Studies based on SOD $1{ }^{\text {G93A }}$ mice have suggested preferential loss of fast motor units before symptom onset in ALS. Although maturational electrophysiological abnormalities have been demonstrated in motoneurons, such changes have not been associated with motor unit type because measuring mechanical properties of motor units to separate fast versus slow populations in young animals is technically challenging. Therefore, using an advanced statistical clustering approach, here we first predicted motor unit types based on motoneuron membrane properties, and then tested the hypothesis that motoneurons forming fast MUs may present excitability changes that are different from motoneurons forming slow MUs. First, we used $k$-means cluster analyses to predict the major types of motor units: predicted slow (PS), predicted fast fatigue resistant (PFR) and predicted fast fatigable (PFF) using rheobase, input resistance, and membrane capacitance as clustering variables (see Materials and Methods). Figure $2 A$ shows the results of $k$-means clustering and the normal curves shown indicate the separation of the three MU populations in both WT and SOD1 ${ }^{\text {G93A }}$ groups. Note that the rheobase and input-resistance of PS, PFR, and PFF TMNs vary in accordance to the expected variation among low-threshold slow MUs and higher threshold fast MUs in both WT and SOD1 ${ }^{\text {G93A }}$ groups. Similarly, membrane capacitance was on average lowest in the PS TMNs and progressively larger in PFR and PFF cells, respectively. Among the clustering variables, rheobase yielded the highest $F$-ratios followed by input resistance and membrane capacitance respectively in both WT and SOD $1{ }^{\text {G93A }}$ (Fig. 2, legend). Based on this classification, we then compared the membrane properties of WT and SOD1 ${ }^{\text {G93A }}$ TMNs among the predicted MU types. We observed that both PFF and PFR SOD1 G93A TMNs showed hyperexcitable shifts marked by reduced rheobase and increased input resistance, whereas PS TMNs did not present significant alterations in these properties (Fig. 2B). Membrane capacitance that was least effective in MU clustering was not different between WT and SOD1 ${ }^{\text {G93A }}$ motor units of all types. Interestingly, there was a significant difference in the proportions of MU types in the WT and SOD $1{ }^{\text {G93A }}$ groups (Fig. 2C) despite proportionate age distribution in the two animal groups (Fig. $2 D$ ). Steady-state frequency-current $(f-I)$ responses for current injections $<600$ 

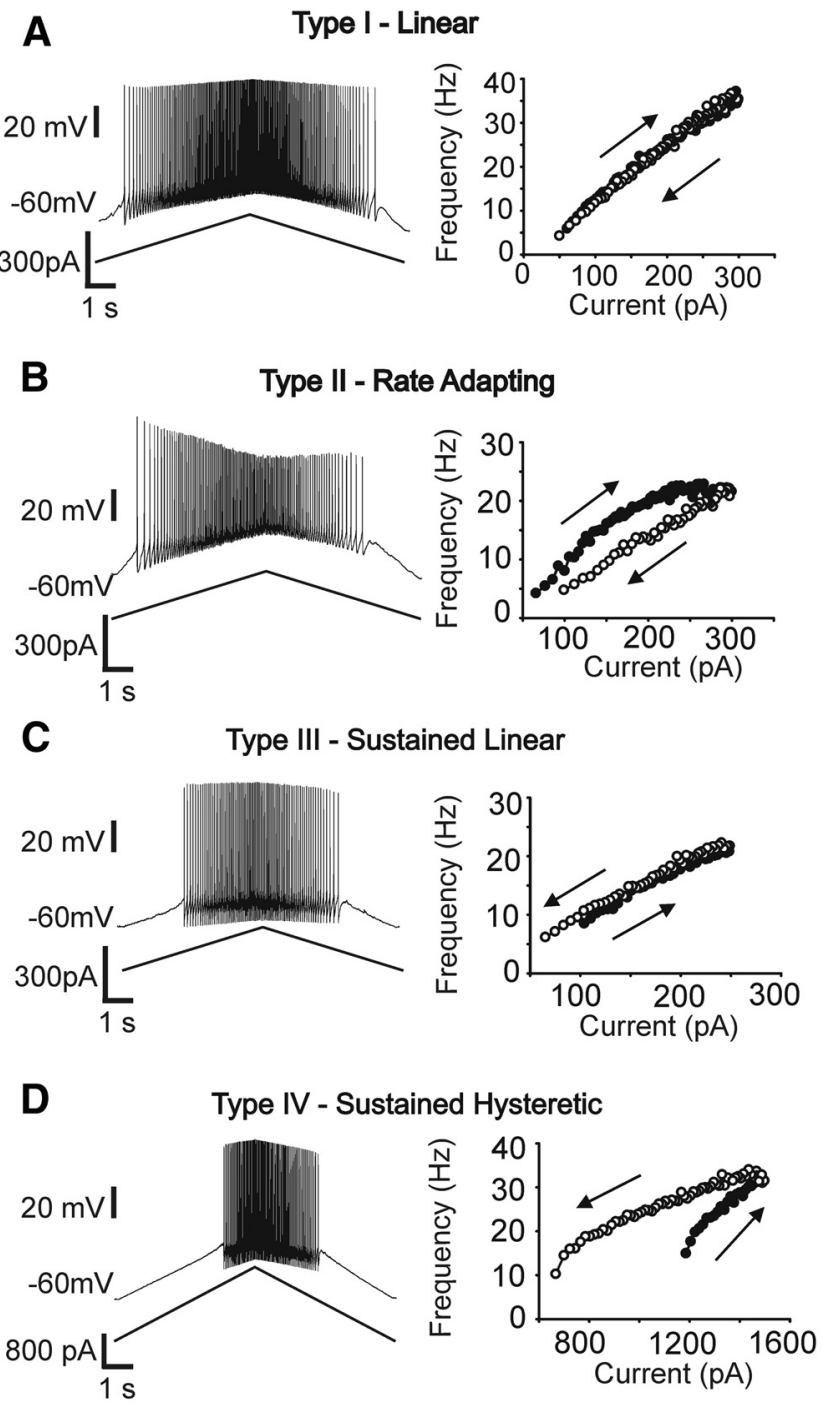

E
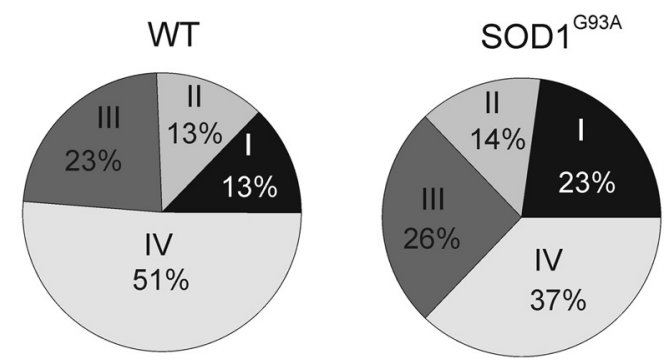

Figure 4. Heterogeneous discharge patterns in TMNs. $\boldsymbol{A}-\boldsymbol{D}$, Membrane voltage responses (left) of four TMNs to injection of triangular ramp currents (bottom traces) and the corresponding plots of instantaneous discharge frequency responses to ascending and descending current ramps (right) are shown by filled and open circles respectively. Arrows point to the direction of the currentramp. Types I-IV refer to the fourtypes of discharge patterns (seesection Discharge patterns of TMNs and their altered distributions in SOD). $E$, Proportions of the four types of discharge patterns found in WT and SOD $1{ }^{693 \mathrm{~A}}$ TMNs were significantly different ( $\chi^{2}$ test: $p=0.0007$ ).

pA showed hyperexcitability in SOD $1{ }^{\text {G93A }}$ PFF TMNs (Fig. 3) wherein WT PFF TMNs did not respond during these lower current injections during steady-state. Note that this is consistent with reduced firing threshold due to reduced rheobase and increased input resistance (Fig. 2B; Table 1). However, for larger current injections $>600$ pA where PFF TMNs of both genotypes responded, no statistically significant differences existed in the steady-state $f-I$ responses between WT and SOD1 ${ }^{\text {G93A }}$ TMNs (two-way repeated-measures ANOVA; Fig. 3). Similarly, the steady-state $f-I$ responses were not different among WT and SOD ${ }^{\text {G93A }}$ PS and PFR TMNs (two-way repeated-measures ANOVA; Fig. $3 B$ ). Interestingly, we noted qualitative differences in the overall pattern of $f-I$ curve distribution among the three predicted MU types in WT versus SOD ${ }^{\mathrm{G} 93 \mathrm{~A}}$ recordings. For instance, over the range of injected current tested (Fig. $3 B$ ), the WT MU groups presented distinct primary range $f-I$ curves (lower arm of bilinear fits) as normally expected within a motor pool, whereas the SOD $1{ }^{\text {G93A }}$ MU group primary range $f-I$ curves overlapped particularly for the PFR and PFF TMNs.

\section{Discharge patterns of TMNs and their altered distribution in} SOD1 ${ }^{\text {G93A }}$ jaw motor pool

The absence of hyperexcitable shifts among SOD $1{ }^{\text {G93A }}$ PS TMNs is consistent with our initial hypothesis that MNs forming fast MUs would show selective disease vulnerable modifications, such as hyperexcitability. However, we sought to determine whether more subtle changes in excitability would be revealed if we examined TMN properties according to discharge patterns. To test this possibility, we classified the TMNs based on their discharge properties in response to a somatic injection of triangular ramp current. As described for spinal motoneurons (Bennett et al., 2001a; Button et al., 2006; Cotel et al., 2009), we observed four qualitatively distinct discharge patterns as shown in Figure $4 A-D$.

Type I neurons show a "linear" relationship in the injected current-frequency response with discharge frequencies matched during both ascending and descending current ramps (Fig. 4A). Type II neurons show rate adaptation during the descending ramp (Fig. 4B). Type III cells show linearity of frequencies during ascending and descending ramps, but with a prominent sustained discharge during the descending ramp that is below the recruitment (or threshold) current (Fig. 4C). Type IV cells also show a sustained discharge during descending ramp accompanied by a counter-clockwise hysteresis in the $f-I$ relationship (Fig. $4 D$ ). All four patterns were found among mutant TMNs as well (data not shown). Although in both WT and mutant Mot V, Types III and IV together were the most abundant and the Type II was the least abundant, proportions of cells with these discharge patterns were significantly different in the mutant motor nucleus ( $\chi^{2}$ proportion test: $p=0.0007$; Fig. $4 E$ ).

\section{Compensatory changes in TMN excitability in SOD1 ${ }^{\text {G93A }}$ mice according to discharge characteristics}

Interestingly, based on the classification according to discharge characteristics, membrane properties were altered among Types I and II, but not in Type III and IV cells in the mutant Mot V compared with WT (Fig. 5A). For example, the Type II cells showed a hyperexcitable shift with a significant reduction in rheobase. However, note that such neurons appear to decrease in proportion in the SOD $1{ }^{\mathrm{G} 93 \mathrm{~A}}$ Mot $\mathrm{V}$ (Fig. $4 E$ ). In contrast, the Type I linear cells, that were more abundant in the mutant Mot $\mathrm{V}$ (Fig. 4E), emerged as a hypoexcitable group with increased rheobase and more depolarized spike voltage threshold (Fig. 5A,B). On average the steady-state $f-I$ response was also lower in mutant Type I TMNs compared with WT but not statistically significant (two-way repeated-measures ANOVA; Fig. 5C). This suggests that such decreases in discharge frequencies shown in Figure $5 C$ are likely a product of increased firing threshold as observed by rheobase and spike threshold changes. Interestingly, both Type I and Type II cells were distributed among PS type TMNs in the 
A

$$
\text { aWT }
$$

$\square \operatorname{SOD} 1^{\text {G93A }}$

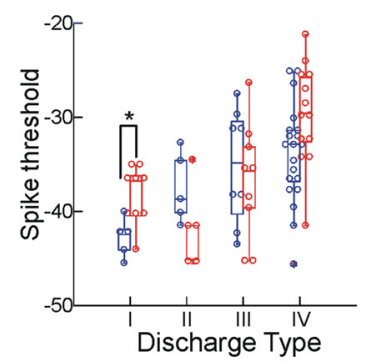

Type I TMNs
B Type ITMNs

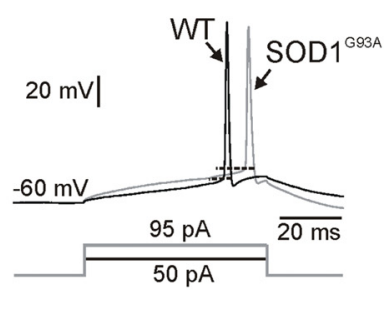

C
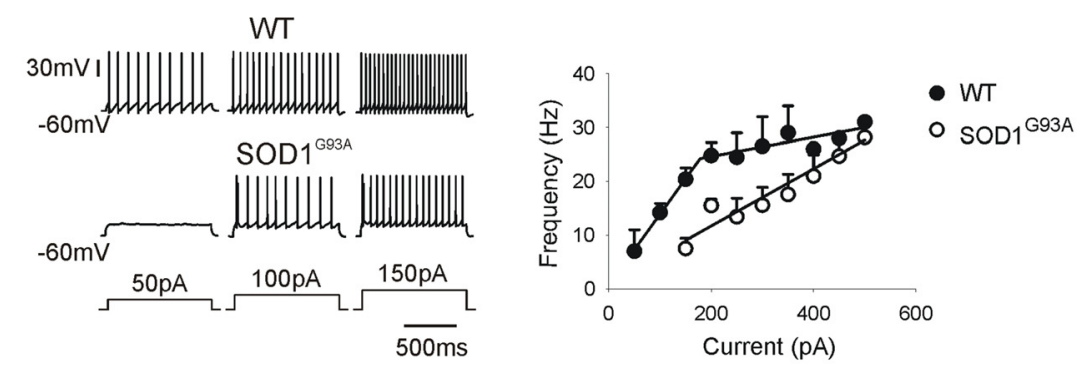

D
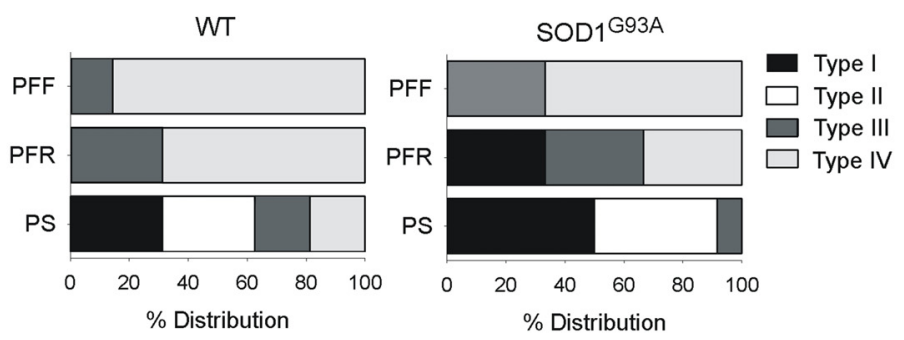

Figure 5. SOD1 ${ }^{\mathrm{G} 93 \mathrm{~A}} \mathrm{TMNs}$ with Type I linear discharge pattern show unexpected changes in excitability. $\boldsymbol{A}$, Comparison of membrane properties based on discharge types between WT (blue) and SOD ${ }^{\text {G93A }}$ (red) TMNs. Rheobase (left) and voltage threshold for spike (right) showed opposite changes among Type I and II cells. Type I cells showed significant increase in rheobase, whereas Type II TMNs showed significant decrease in rheobase (Student's $t$ test, ${ }^{*} p=0.034,{ }^{* *} p=$ 0.0103 ). Spike threshold was significantly depolarized in Type I cells (Student's $t$ test, ${ }^{*} p=0.0131$ ). Units of rheobase and spike threshold are $\mathrm{pA}$ and $\mathrm{mV}$, respectively. Error bars indicate SD. $\boldsymbol{B}$, Examples showing increased rheobase and spike threshold in SOD $1^{\mathrm{G} 93 \mathrm{~A}}$ Type I TMNs compared with WT. C, Left, Membrane voltage responses to increasing levels of $1 \mathrm{~s}$ current injection (bottom traces) in WT (top trace) and SOD $1{ }^{\text {G93A }}$ (middle traces) Type I TMNs. Right, Average steady-state frequency-current responses in WT ( $n=5$ cells from 5 animals) and SOD $1^{\text {G93A }}$ ( $n=9$ from 8 animals) Type I TMNs. Error bars indicate SEM and black lines indicate linear fits to TMN frequency range(s). D, Distribution of different discharge types among PS, PFR, and PFF TMNs. Bar charts show percentage composition of the four discharge types among the predicted MU types.

WT group, whereas Types III and IV were largely PFR and PFF cells (Fig. 5D). However, in the mutant, the proportional increase in the Type I cells (Fig. 4E) was partly distributed among PFR TMNs suggesting a possible homeostatic mechanism of excitability compensation in the fast $\mathrm{MN}$ group through increases in the proportion of hypoexcitable cells in the jaw motor pools. Concomitantly, the SOD $1{ }^{\mathrm{G} 93 \mathrm{~A}}$ group also showed a decrease in Type III and IV cells that formed the PFR and PFF groups. Overall, PS TMNs were heterogeneous showing all four discharge types and the proportions of cells with specific discharge properties were different in the mutant.

\section{Motor unit prediction in oculomotor nucleus and lack of changes in SOD $1{ }^{\mathrm{G} 93 \mathrm{~A}}$ oculomotor motoneuron membrane properties}

Given that mutant SOD1 is ubiquitously expressed we tested whether the observed changes in MN excitability based on $\mathrm{MU}$
Discharge patterns of OMNs and lack of changes in the SOD $1{ }^{\mathrm{G} 93 \mathrm{~A}}$ oculomotor nucleus

An examination of the discharge characteristics of OMNs in response to triangular ramp current injections revealed three types of discharge patterns (Fig. 8A-C). Type I corresponds to cells showing a linear $f-I$ relationship on ascending and descending current ramps (Fig. 8A). Type II corresponds to "rate adapting" cells that show frequency adaptation during the descending ramp (Fig. 8B). Type III corresponds to the "sustained linear" pattern with an extended frequency range during the descending ramp below the firing threshold of the ascending ramp phase (Fig. 8C). All three patterns were found among SOD $1{ }^{\mathrm{G} 93 \mathrm{~A}} \mathrm{OMNs}$ as well. Moreover, there was no significant redistribution of the discharge types in the SOD $1{ }^{\mathrm{G} 93 \mathrm{~A}}$ Mot III compared with WT (Fig. $8 D$ ) and we did not observe any subtype specific excitability changes. Additionally, the distribution of the discharge types was similar among PS and PF MU types (Fig. 8E) among WT and SOD $1{ }^{\text {G93A }}$ OMNs. 
Jaw closer motor pool simulations and predicted force development

In summary, brainstem motoneurons including the trigeminal and oculomotor neurons presented here do not show hyperexcitability in the form of increased $f-I$ gain at P8-P12. However, rheobase and the proportions of cells showing different discharge characteristics show complex changes in the ALS vulnerable TMNs but not in the ALS-resistant OMNs. Specifically, TMNs predicted to form fast MUs show reduced rheobase and PS TMNs with linear discharge patterns show increased rheobase and are increased in proportions. If such opposite changes were to occur in the input thresholds of slow and fast MNs in a jaw motor pool, we hypothesized that there could be alterations in $\mathrm{MN}$ recruitment and muscle force development early on. To test such a possibility and to predict changes in the muscle force development, we used a simple motor pool model of a jaw closer motor pool.

The simulation model was constructed based on similar models for spinal motor pools (Heckman and Binder, 1991) that allowed explicit parameterization of recruitment thresholds and steady-state $f-I$ gains. The model enabled simulation of muscle isometric forces due to changes in TMN recruitment thresholds based on observed changes in rheobase values. For simplicity, we only represent slow and fast MNs and combine FR and FF as fast MNs to simulate SOD1 ${ }^{\mathrm{G} 93 \mathrm{~A}}$ changes in recruitment threshold values and further assume no changes in muscle properties in the mutant at this presymptomatic age.

A jaw closer masseter pool consisting of 100 TMNs was constructed to estimate normal (WT) and altered (SOD1 ${ }^{\mathrm{G} 93 \mathrm{~A}}$ ) isometric forces. Briefly, each model MN was defined using six experimentally derived parameters including threshold recruitment current $\left(I_{\text {thresh }}\right)$ and frequency $\left(f_{\text {thresh }}\right)$, steady-state primary $\left(\mathrm{G}_{1}\right)$ and secondary $\left(\mathrm{G}_{2}\right)$ gains, primary to secondary transition current $\left(I_{\text {trans }}\right)$, and frequency $\left(f_{\text {trans }}\right)$ derived from our experimental data (see Materials and Methods for detailed definitions of terms). The $\mathrm{MN}$ and motor unit properties for every fifth $\mathrm{MN}$ are listed in Table 3.

Based on the observed $f-I$ gain and rheobase values in WT and mutant TMNs, we simulated three scenarios as follows:

\section{Simulation of standard motor pool behavior}

(1) For the standard condition, the primary $f-I$ gains were set as $G_{1}=0.1 \mathrm{~Hz} / \mathrm{pA}$ for all 100 neurons. The secondary $f-I$ gain $\mathrm{G}_{2}$ was set at $0.06 \mathrm{~Hz} / \mathrm{pA}$ for the first 30 neurons representing the slow MUs, and at $0.05 \mathrm{~Hz} / \mathrm{pA}$ for the remaining 70 neurons representing the fast MUs. These values approximate our experimental values. The resulting $f-I$ curves for every $10^{\text {th }}$ neu-

B cells.
WT
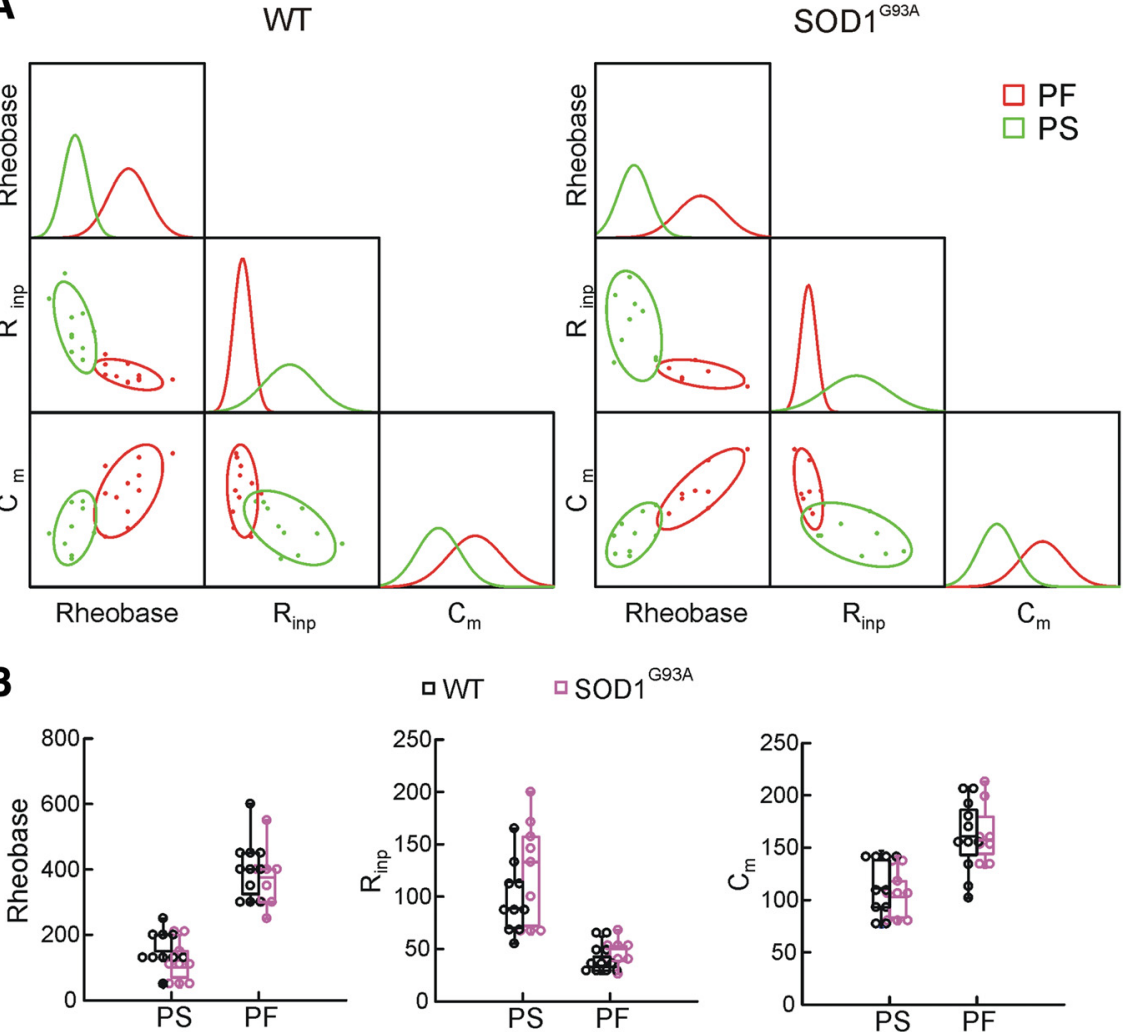

aWT

$\square \mathrm{SOD} 1^{\text {G93A }}$
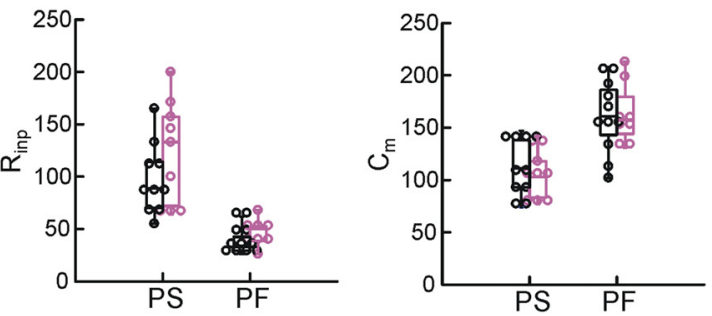

D

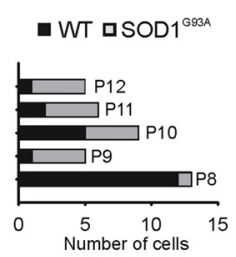
including rheobase, $R_{\text {inp }}$ and $C_{\mathrm{m}}$ showing the result of $k$-means clustering based classification of motor units with PS in green and PF in red, in both WT (left) and SOD $1{ }^{693 A}$ (right) OMNs. The diagonal cells show the normal curves for each MU group. In WT the F-ratios were 52.7, 31.3, and 11.7, and in the mutant these values were 62.9, 17.9, and 21.5, respectively for rheobase, input resistance, and membrane capacitance. $\boldsymbol{B}$, Comparison of membrane properties of MU groups between WT (black) and SOD $1{ }^{\text {G93A }}$ (a) $0 M N$ s. No statistical differences were found. Error bars indicate $S D$. $A, B$, Units of rheobase, $R_{\text {inp }}$ and $C_{\mathrm{m}}$ are $\mathrm{pA}, \mathrm{M} \Omega$, and $\mathrm{pF}$, respectively. $\boldsymbol{C}$, Percentage of cells classified as PS and PF units in WT and mutant groups. $\boldsymbol{D}$, Distribution of cells across the age range considered (P8-P12). Data from 14 WT mice $(n=21)$ and 12 SOD1 ${ }^{\text {G93A }}$ mutant mice $(n=17)$, where $n$ is the number of

Table 2. Membrane properties of WT and SOD1 ${ }^{\text {G93A }}$ OMNs classified by predicted MU type

\begin{tabular}{|c|c|c|c|c|}
\hline \multirow[b]{2}{*}{$\begin{array}{l}\text { Membrane } \\
\text { property }\end{array}$} & \multicolumn{2}{|l|}{ PS } & \multicolumn{2}{|l|}{ PF } \\
\hline & WT $(n=10)$ & $\begin{array}{l}\text { SOD1 }{ }^{\text {G93A }} \\
(n=9)\end{array}$ & WT $(n=11)$ & $\begin{array}{l}S^{S O D 1^{693 A}} \\
(n=8)\end{array}$ \\
\hline$C_{m}, p F$ & $114.2 \pm 8.6$ & $105.1 \pm 7.7$ & $161.1 \pm 10.4$ & $163.3 \pm 10.1$ \\
\hline${ }_{n p}, M \Omega$ & $97.3 \pm 10.6$ & $123.5 \pm 16.5$ & $37.2 \pm 3.5$ & $47.0 \pm 4.5$ \\
\hline RMP, $\mathrm{mV}$ & $-56.9 \pm 1.8$ & $-57.9 \pm 1.3$ & $-59.1 \pm 1.2$ & $-59.3 \pm 1.0$ \\
\hline heobase, pA & $162.0 \pm 17.3$ & $113.9 \pm 20.0$ & $400.0 \pm 27.0$ & $368.8 \pm 32.6$ \\
\hline P threshold, mV & $-43.7 \pm 1.9$ & $-42.4 \pm 2.0$ & $-40.8 \pm 1.7$ & $-40.5 \pm 1.4$ \\
\hline height, $\mathrm{mV}$ & $88 \pm 3.6$ & $87.6 \pm 2.3$ & $93.7 \pm 1.8$ & $92.0 \pm 2.9$ \\
\hline P half-width, ms & $0.9 \pm 0.1$ & $1.0 \pm 0.1$ & $0.7 \pm 0.03$ & $0.7 \pm 0.04$ \\
\hline AHP, mV & $-4.7 \pm 1.2$ & $-7.2 \pm 1.6$ & $-2.8 \pm 0.3$ & $-2.6 \pm 0.4$ \\
\hline
\end{tabular}

Values reported as mean \pm SEM. Student $t$ tests were performed for statistical comparison between WT and SOD $1^{\mathrm{G} 93 \mathrm{~A}}$ neurons within the two predicted MU types. 
A

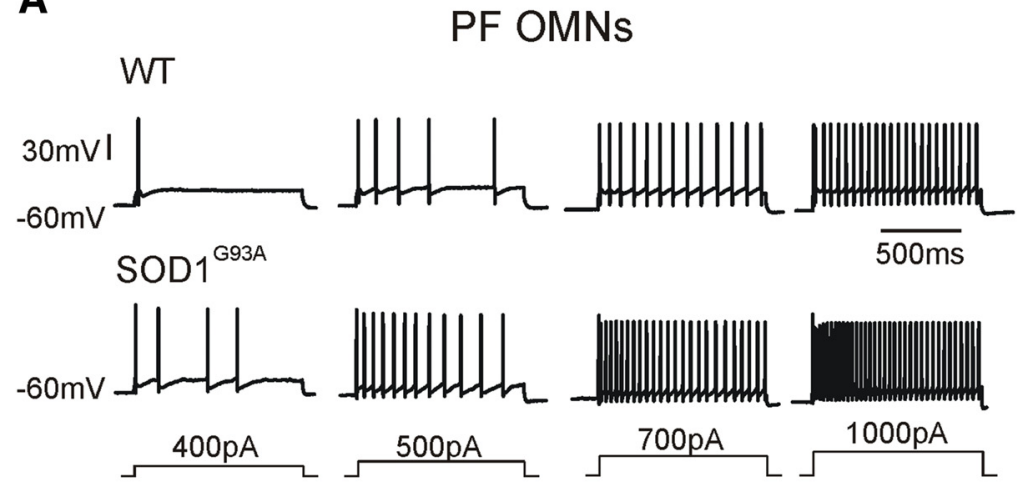

B
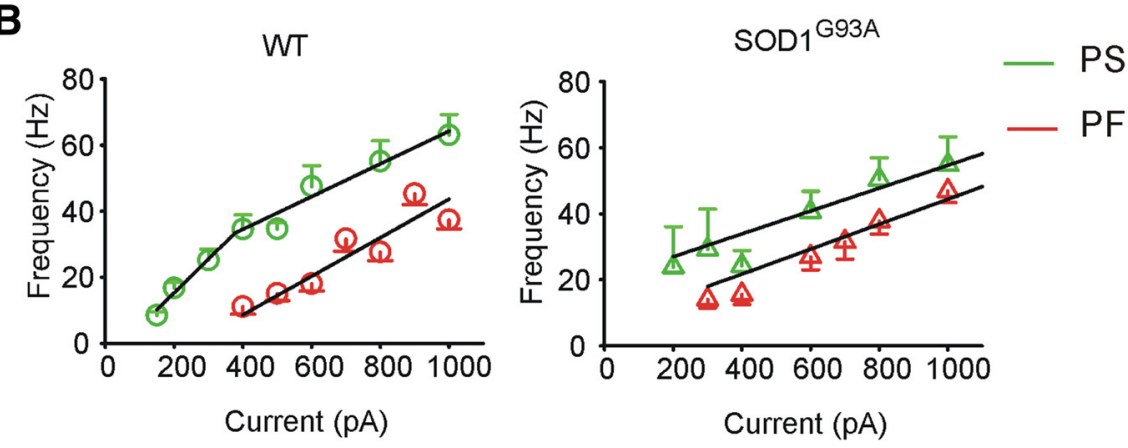

Figure 7. Frequency-current responses in the predicted $0 M N$ motor units. $A$, Membrane voltage responses to increasing levels of 1 s current injection (bottom traces); top and bottom traces show example PF OMNs from WT and SOD1 ${ }^{\text {G93A }}$ mice respectively. $B$, Average steady-state frequency-current responses in WT (circles) and SOD1 ${ }^{\text {G93A }}$ (triangles) OMNs. The PS (WT: $n=9$ cells from 6 animals; SOD1 ${ }^{\text {G93A. }} n=5$ cells from 4 animals) and PF cells (WT: 11 cells from 10 animals; SOD ${ }^{693 \mathrm{~A}}: n=7$ cells from 6 animals) are depicted in green and red, respectively. Error bars indicate SEM, and black lines indicate linear fits to OMN frequencies. Among the respective MU groups, there were no statistically significant differences between WT and SOD1 ${ }^{\text {G93A }}$ (two-way repeatedmeasures ANOVA).

ron are shown in Figure 9A (left). To generate $I_{\text {thresh }}$ values for individual MNs, first we constructed a line with a certain slope and offset that resulted in a range of $100-950 \mathrm{pA}$ from the first to the $100^{\text {th }}$ neuron in the pool. This provided a $\sim 10$-fold range of $I_{\text {thresh }}$ across the pool reflecting the rheobase range in our data. Each MN in the pool was assigned $I_{\text {thresh }}$ value along this line with evenly spaced increase in $I_{\text {thresh }}$ between consecutive model neurons (Fig. 9A, middle). The corresponding control isometric muscle force is shown in Figure 9A (right).

Simulation of recruitment threshold changes in SOD ${ }^{\text {G93A }}$ TMNs (2) We modeled the observed aberration in MN recruitment threshold of fast and slow SOD $1{ }^{\mathrm{G} 93 \mathrm{~A}}$ TMNs in two steps. First, we compressed the $I_{\text {thresh }}$ range of only the fast MNs to represent the observed reduced threshold for recruitment. We did so, by altering the $I_{\text {thresh }}-\mathrm{MN}$ line under standard conditions to a bilinear distribution of $I_{\text {thresh. }}$. The $I_{\text {thresh }}$ values of slow MUs remained unaltered, whereas those of the fast MNs were now sampled along a line with reduced slope resulting in a compression of $I_{\text {thresh }}$ range across the fast MUs as shown by the red trace in Figure $9 B$ (left). The resulting change in the muscle isometric force is shown by the red trace in Figure 9B (right). Note that reduced recruitment thresholds of large TMNs could profoundly enhance the steepness of the sigmoidal force curve. Finally, to model the concomitant $I_{\text {thresh }}$ increases in slow MUs, we increased the slope of the lower arm of the $I_{\text {thresh }}-\mathrm{MN}$ line that resulted in an increase in the sampled $I_{\text {thresh }}$ values for slow MU neurons (Fig. 9B, left, blue trace). Note that such reorganization of $I_{\text {thresh }}$ values further simulates an increased proportion of low-threshold smaller neurons. This modification resulted in partial compensation of the isometric force as shown in Figure $9 B$ (right, blue trace).

\section{Simulation of $\mathrm{f}-\mathrm{I}$ gain changes}

(3) Because increased $f-I$ gain has been noted in other ALS-vulnerable brainstem and spinal MNs we tested the potential effect of changes in $f-I$ gains. We simulated opposite changes in $f-I$ gains of fast and slow MU TMNs by increasing the gains of fast MU neurons and decreasing the gains of slow MU neurons as in Figure 9C (left). The corresponding isometric force is shown in Figure $9 C$ (right). Note that the $f-I$ gain changes produce a negligible effect on force development (compare green trace with the black control trace in the figure).

In Figure $9 D$, we show a comparison between the force deviations due to $I_{\text {thresh }}$ and $f-I$ gain changes detailed above. Note from the blue and green curves in Figure $9 D$ that hypoexcitability in $I_{\text {thresh }}$ of slow MU TMNs can suppress the initiation of force development. However, as input levels increase and larger forces develop, note the hypoexcitability in $I_{\text {thresh }}$ of lowthreshold TMNs compensates for the hyperexcitibility of $I_{\text {thresh }}$ in fast MU TMNs. Moreover $f-I$ gain changes considered here resulted in negligible force deviation from standard condition. Finally, when both $f-I$ gain changes and $I_{\text {thresh }}$ changes were simultaneously simulated the resulting isometric force shows a reduction in the dynamic range of the motor pool input-output relationship (Fig. 9E). The distortion in the isometric force curve (Fig. 9E, orange) compared with control curve (Fig. $9 E$, black) highlights a change in the equilibrium of the motor pool function.

\section{Discussion}

A significant finding of this study shows that ALS-vulnerable SOD $1{ }^{\mathrm{G} 93 \mathrm{~A}}$ MNs exhibit more complex changes in excitability than previously reported. Specifically, SOD1 ${ }^{\mathrm{G} 93 \mathrm{~A}}$ TMNs predicted to form fast MUs show a hyperexcitable shift in rheobase. However, a surprising observation was that a subset of predicted slow MU TMNs in SOD1 ${ }^{\mathrm{G} 93 \mathrm{~A}}$ cells with distinct discharge properties increased in proportions and showed a hypoexcitable shift in rheobase and voltage threshold for spike initiation. Such excitability changes were absent in the disease-resistant OMNs. The observed changes in SOD $1{ }^{\mathrm{G} 93 \mathrm{~A}}$ TMNs are expected to alter motor unit recruitment and jaw muscle force development. To test this hypothesis, we constructed a simplified JC motor pool model using computer simulations. Model results suggest that hyperexcitable alterations in recruitment threshold of fast motor units would result in a steeper input-output relationship of the motor pool, suggesting more rapid muscle force development. Furthermore, such rapid force development can be partly compensated by the observed hypoexcitable shifts and increased slow motor unit composition in the mutants. Together these changes could reduce the dynamic range of motor pool input- 
output function. Moreover, near low levels of pool inputs, hypoexcitability of slow TMNs can suppress force initiation.

Motor unit prediction and distribution of electrophysiological properties

Using $k$-means clustering approach we were able to successfully identify three clusters potentially corresponding to slow, fast fatigue resistant and fast fatigable TMNs and two clusters potentially corresponding to slow and fast OMNs. The F-ratio indicative of the power of the clustering variable was maximal for rheobase followed by input resistance and capacitance in TMNs consistent with the greater accuracy of MU prediction using rheobase as a discriminant variable in previous studies on spinal MNs (Fleshman et al., 1981; Zengel et al., 1985; but see Gardiner, 1993). A similar trend in F-ratio was also noted in OMN clustering, however, the input resistance was less powerful in MU prediction compared with TMNs.

Although the high-threshold MNs are unambiguously $\alpha$-motoneurons that innervate the extrafusal muscles, some lowthreshold MNs could be gamma MNs that innervate the muscle spindles. Parameters that may distinguish gamma MNs from $\alpha$ MNs, such as higher antidromic stimulation threshold (in vivo) or lack of monosynaptic responses during afferent stimulation (Sessle, 1977) are both not feasible and definitive methods to use in the neonatal in vitro brain slice preparation. Although we have previously demonstrated stimulation techniques in brain slices to study the physiology and pharmacology of synaptic inputs from the sensory mesencephalic nucleus to TMNs (Trueblood et al., 1996; Del Negro and Chandler, 1998), many of these connections are lost during brain-slice preparation and cannot be used as a reliable approach to test the lack of afferent connections to segregate gamma TMNs. Furthermore, gamma TMNs are spontaneously active in vivo (Sessle, 1977) and we did not encounter such MNs in our in vitro dataset.

\section{Assumptions and limitations of motor} pool simulation model

First, we assume that our TMN dataset predominantly represents the JC motor pool(s) neurons because the TMNs filled with the red dye (AlexaFluor 568) during patch-clamp recording were identified post hoc in the dorsolateral Mot V where JC MNs are localized (Mizuno et al., 1975). Second, we use membrane properties including rheobase and input resistance that are suggested to predict MU types with $>90 \%$ accuracy (Zengel et

B

C
A Type I - Linear

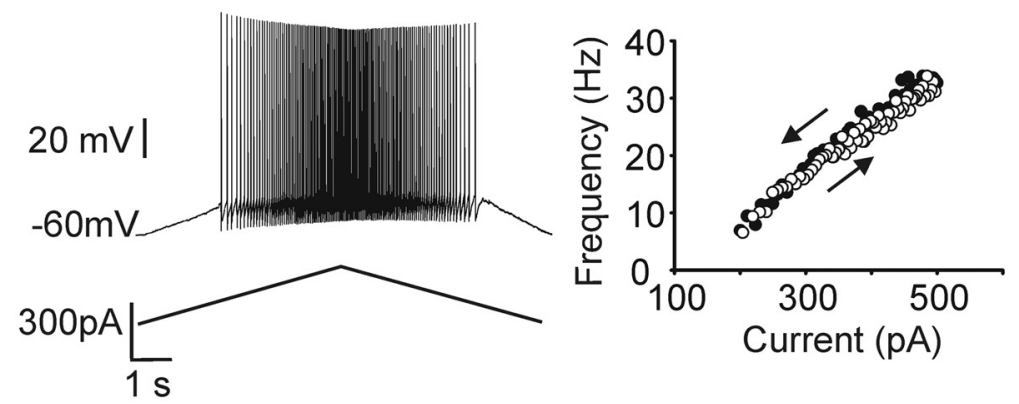

Type II - Rate Adapting
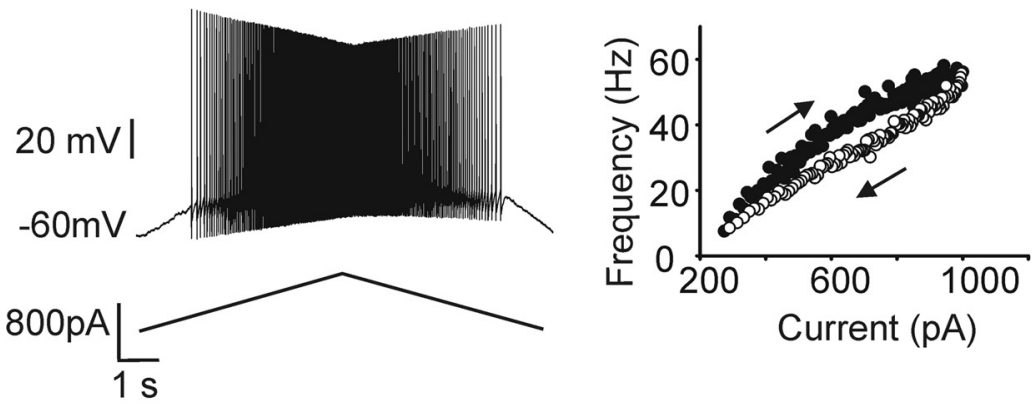

Type III - Sustained Linear
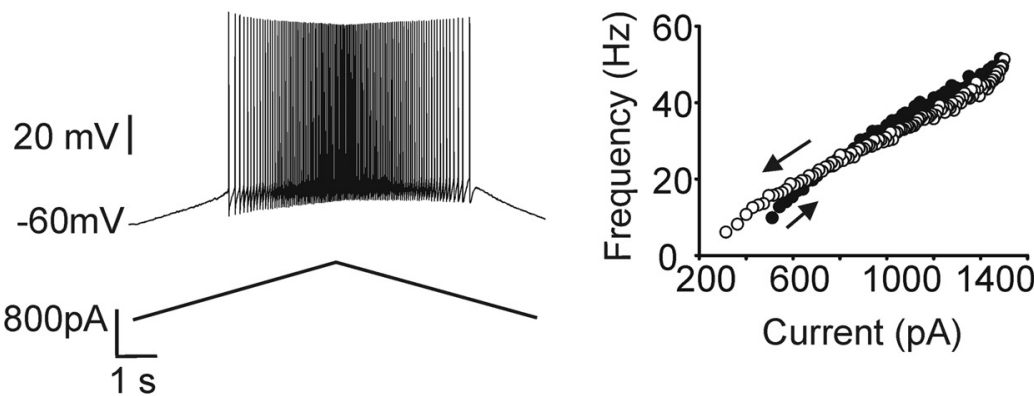

D
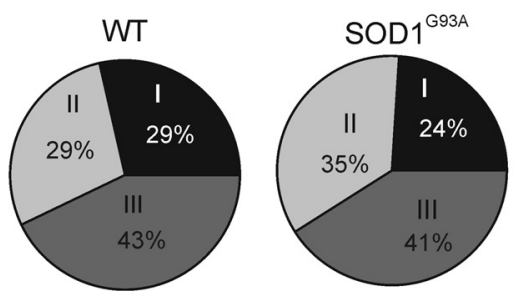

E

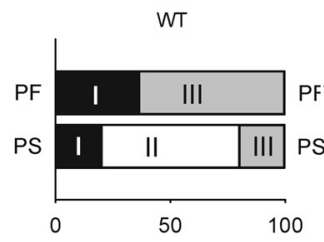

SOD $1^{\text {G93A }}$

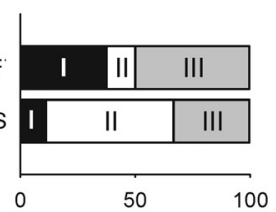

Figure 8. Discharge patterns of OMNs. A-C, Membrane voltage responses (left) of three OMNs to injection of triangular ramp currents (bottom traces) and the corresponding plots of instantaneous discharge frequency responses to ascending and descending current ramps (right) are shown by filled and open circles respectively. Arrows point to the direction of current ramp. Types I-III refer to the three types of discharge patterns (see text). $\boldsymbol{D}$, Proportions of the three types of discharge patterns found in WT and SOD1 ${ }^{\text {G93A }}$ OMNs were similar and not statistically different ( $\chi^{2}$ proportionality test). $\boldsymbol{E}$, Horizontal bar charts show percentage distribution of the three discharge types among PS and PF OMNs.

al., 1985). We further directly extrapolate the $\mathrm{MN}$ recruitment threshold and $f-I$ gains found in this dataset into a single JC motor pool model. Nonetheless, due to the simplified representation of each model MN based on experimentally derived properties (see Materials and Methods, and Results), the insight from the model simulations that rheobase change would have a profound effect on steady-state motor pool input-output relationship should be reasonable. However, more de- 
Table 3. Simulated jaw motor unit properties

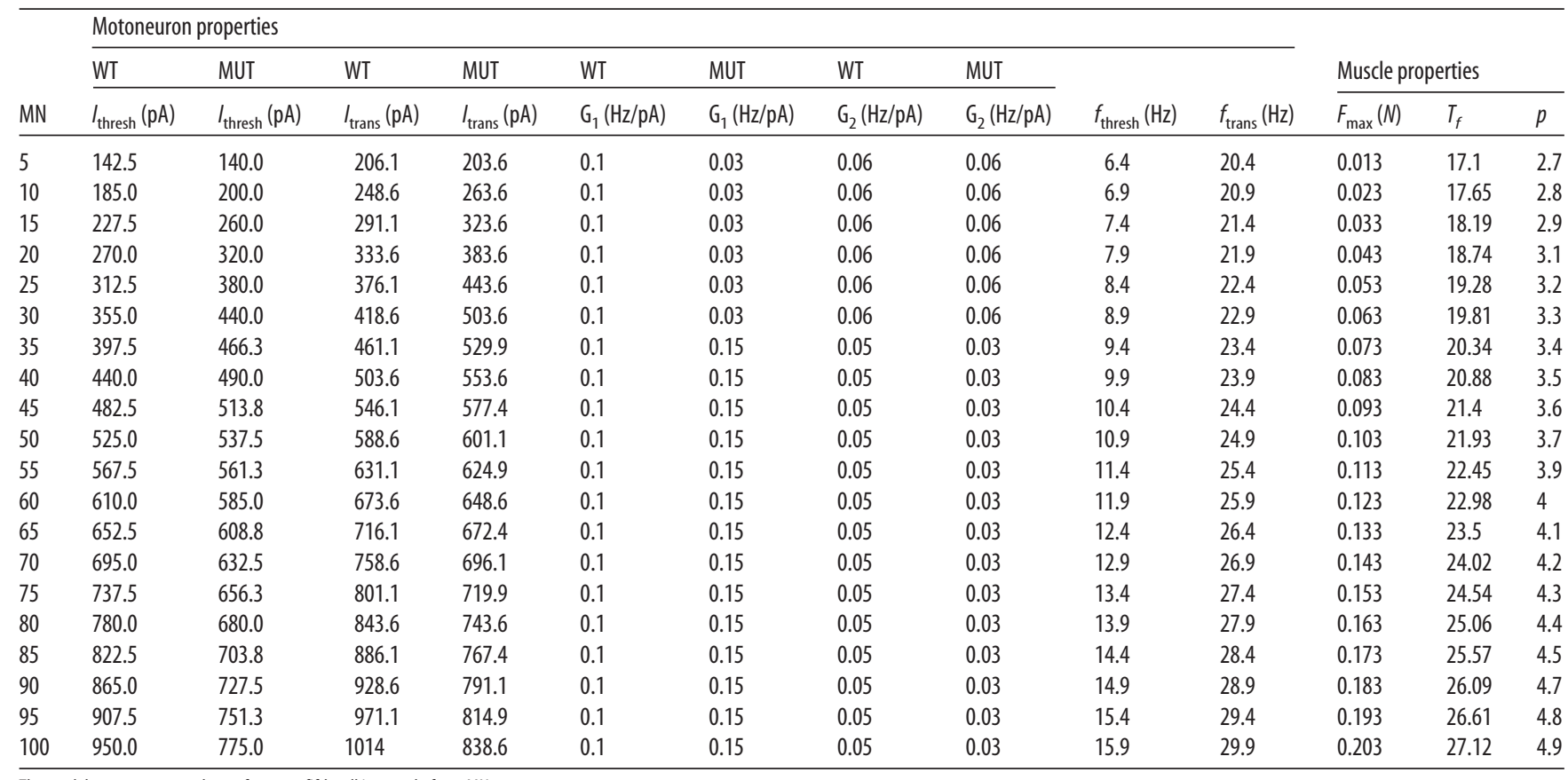

The model parameters are shown for every fifth cell in a pool of $100 \mathrm{MNs}$.

tailed MN models are essential to examine the effect of alterations in $\mathrm{MN}$ discharge patterns on motor pool behavior. Last, we assume no aberrations in the muscle fiber properties in the mutant compared with WT that requires empirical validation.

\section{Discharge patterns of TMNs and OMNs}

Similar to spinal MNs (Bennett et al., 2001a; Button et al., 2006; Turkin et al., 2010), we found that the brainstem TMNs and OMNs also displayed heterogeneous discharge patterns in response to triangular ramp current injections. However, the OMNs were somewhat less heterogeneous. Specifically, all four discharge patterns described for spinal MNs were present among TMNs, whereas only three types of patterns were present among OMNs. In comparison with discharge patterns observed in TMNs, Type I OMNs were qualitatively similar. However, Type II OMNs showed lesser degree of rate adaptation than TMNs. For example, for the Type II OMN shown in Figure $7 B$, the firing frequencies during descending ramp gradually merge with the ascending frequencies, thus abolishing the rate adaptation near recruitment frequency. Among Type III OMNs often an initial phase of rate adaptation was observed during the descending current ramp followed by a crossover of frequencies resulting in sustained firing. Such frequency crossover was not observed in TMNs. Type IV cells with a sustained hysteretic pattern were not observed among OMNs. Interestingly there was a significant change in the proportion of cells displaying the different discharge patterns in TMNs compared with OMNs in the SOD 1 G93A animals. This suggests an altered homeostasis in the excitability of the vulnerable Mot V.

\section{Effect of development on MN membrane properties}

Based on in vitro studies, membrane properties of motoneurons change during the postnatal period (for review, see Carrascal et al., 2005). Moreover, among brainstem motoneurons, some membrane properties show opposite changes between different brainstem motor nuclei. For example, rheobase is suggested to decrease with postnatal age in oculomotor neurons (Carrascal et al., 2006), whereas it increases with postnatal age in hypoglossal neurons (Núñez-Abades et al., 1993). We show that the two types of postnatal age-matched motoneurons (TMNs and OMNs) present fundamental differences in the membrane properties in the mutant compared with WT. The cells were proportionately distributed across ages considered (P8-P12) in both genotypes for TMNs (Fig. 2D). For OMNs, we noted a slight bias toward P8 among WT and toward P12 in SOD ${ }^{\mathrm{G} 93 \mathrm{~A}}$. Although this was a random occurrence, we further note that this did not lead to manifestation of age-related differences between WT and SOD $1{ }^{\text {G93A }}$ groups because we did not observe significant changes in any of the measured membrane properties between the two groups among either of the predicted MU types. Moreover, developmental changes in OMN membrane properties are more dramatic at $\mathrm{P} 0-\mathrm{P} 5$, whereas such changes are not significant between P6-P10 and P11-P15 (Carrascal et al., 2006). Together, our results on ALSvulnerable TMNs clearly demonstrate motor unit specific modifications in the mutant motoneurons, whereas the ALSresistant mutant OMNs do not present such changes in the postnatal age range tested.

\section{Possible mechanisms underlying MN excitability changes}

Spinal MNs with sustained discharge patterns showed large persistent inward sodium and calcium currents (PICs) activated by supraspinal monoaminergic inputs. These PICs are modulated following spinal trauma and in ALS (Li and Bennett, 2003; Quinlan et al., 2011). Alternatively, MNs with linear discharge patterns are likely to have negligible PICs (Bennett et al., 2001a; Li et al., 2004). The fact that these two types of discharge patterns showed opposite changes in proportion and excitability in TMNs suggests that PICs play an integral role in the homeostatic regulation of MN and motor pool excitability (Elbasiouny et al., 2010; Martin et al., 2013). Recently we reported evidence for tonic GABAergic currents that can modulate TMN excitability and 
their downregulation in SOD1 ${ }^{\text {G93A }}$ TMNs (Venugopal and Chandler, 2012). Such reductions in tonic inhibition may underlie the reduced firing threshold in large TMNs. Alterations in potassium (Wainger et al., 2014) and persistent sodium conductance (Kuo et al., 2005; Bellingham, 2013) may also play a role. Concomitant opposite changes in large versus small TMN excitability highlights the existence of mechanisms coupling the excitability of different MNs within a motor pool. Noncell autonomous changes in astrocytes could play a role in such coupling (Bataveljić et al., 2012).

\section{Role for intrinsic MN excitability changes in ALS pathogenesis}

Motoneuron hyperexcitability has been widely reported in ALS patients (Vucic and Kiernan, 2006) and in animal and cell culture models (Pieri et al., 2003; Kuo et al., 2004; Durand et al., 2006; van Zundert et al., 2008; Quinlan et al., 2011; Wainger et al., 2014). Presymptomatically, hyperexcitability could make MNs hyperresponsive to glutamatergic inputs in turn leading to excessive intracellular calcium causing ER stress and triggering apoptotic cascade through mitochondrial overload (Grosskreutz et al., 2010; van Zundert et al., 2012). Therefore, factors reducing hyperexcitability are considered potential therapeutic targets. However, if we consider our results, it is clear that hypoexcitability concomitantly occurs in a distinct population of low-threshold TMNs with distinct discharge properties compared with the high-threshold cells that show hyperexcitable shifts. Within a homogeneous motor pool, hypoexcitability in low-threshold motoneurons can restrict/ suppress muscle activation as shown by the model. Indeed, inhibiting MN excitability presymptomatically has been shown to induce pathological cellular responses and enhanced compensatory responses, whereas enhancing excitability was neuroprotective (Saxena et al., 2013).Together with the additional findings that hyperexcitability is not observed in adult mutant mice (Delestrée et al., 2014), it appears that a change toward hypoexcitability may indeed represent the disease process, whereas early hyperexcitability may represent a compensation. Therefore, identifying the distinct cellular and molecular properties of cells displaying reduced excitability in addition to hyperexcitability would serve as opportunistic targets for investigation into the underlying mechanisms contributing to disease progression.



Standard simulation: control pool behavior



C Modeling possible $\mathrm{f}-\mathrm{I}$ gain changes and its effect on motor pool behavior
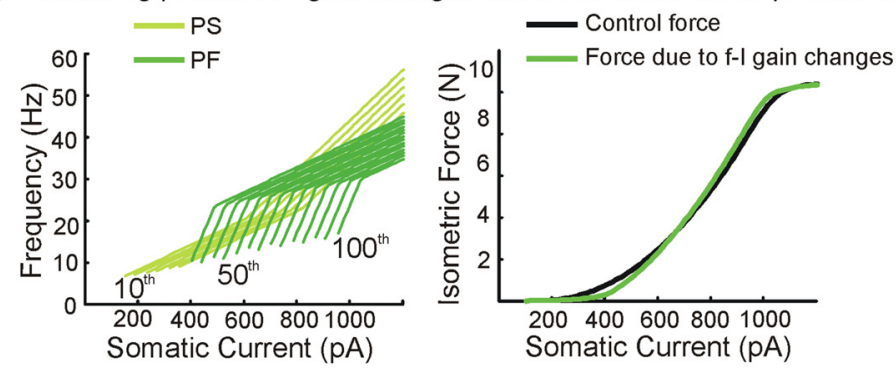

D Deviation from control force

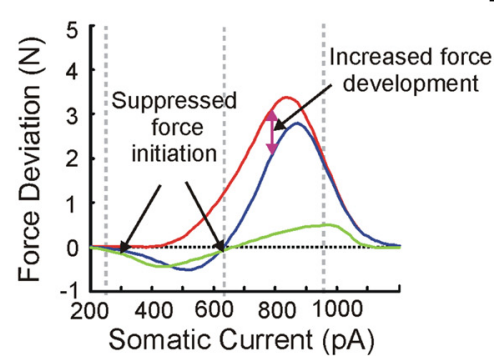

E Reduced motor pool dynamic range

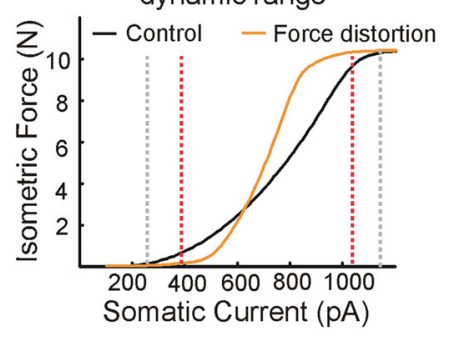

Figure 9. Simulation of effects of recruitment and $f-$ I gain changes on JC motor pool behavior. $A$, Standard/control condition. Left, Frequency-current curves shown for every $10^{\text {th }}$ model MN with PS MNs represented in gray and PF MNs in black. Middle, An evenly spaced increasing distribution of $I_{\text {thresh }}$ across the motor pool. Right, Resultant isometric force shown as a function of neural excitation (somatic current). $\boldsymbol{B}$, Left, Posited shifts in the distribution of $I_{\text {thresh }}$ across the pool in the mutant TMNs. In red is shown the modeled reduction in rheobase of PFMNs obtained by a reduction in the slope of the linear $I_{\text {thresh }}$ distribution of the $31^{\text {st }}-100^{\text {th }}$ cell. The blue trace shows a steeper distribution of $I_{\text {thresh }}$ for PS MNs $\left(1^{\text {st }}-30^{\text {th }}\right.$ cell) reflecting an increase in rheobase values of these cells and reduced slope of $I_{\text {thresh }}$ distribution of $31^{\text {st }}-100^{\text {th }}$ cell representing the reduced rheobase among PF MNs. Right, The corresponding alteration in the isometric muscle force is shown in red and blue, respectively, together with the standard force (black). C, Effect of $f$-lgain changes on motor pool behavior. Left, Modified $f$-l curves shown for every $10^{\text {th }}$ model MN with PS MNs represented in light green and PF MNs in dark green. Right, The corresponding alteration in the isometric muscle force is shown (green) together with the standard force (black). D, Force deviations from control condition are shown with: (1) only $f-l$ gain changes in green, (2) only $I_{\text {thresh }}$ changes only among PF MNs in red, and (3) only $I_{\text {thresh }}$ changes in both PF and PS MNs in blue. Dashed vertical lines highlight two regions: a left region showing deviations $<0$ for blue trace suggesting suppression of force initiation due to hypoexcitability, a right region showing deviations $>0$ for blue trace suggesting compensatory effect to limit $P F$ TMN hyperexcitability. The green trace shows force deviation due to $f$ - I gain changes. $\boldsymbol{E}$, Overall distortion in the isometric force due to both $I_{\text {thresh }}$ and $f-I$ gain changes is shown in orange together with the standard force in black. The region between red vertical lines shows reduced motor pool dynamic range compared with the region between gray vertical lines for control simulation. 


\section{References}

Angenstein F, Niessen HG, Goldschmidt J, Vielhaber S, Ludolph AC, Scheich $\mathrm{H}$ (2004) Age-dependent changes in MRI of motor brain stem nuclei in a mouse model of ALS. Neuroreport 15:2271-2274. CrossRef Medline

Bataveljić D, Nikolić L, Milosević M, Todorović N, Andjus PR (2012) Changes in the astrocytic aquaporin- 4 and inwardly rectifying potassium channel expression in the brain of the amyotrophic lateral sclerosis SOD1(G93A) rat model. Glia 60:1991-2003. CrossRef Medline

Bellingham MC (2013) Pre- and postsynaptic mechanisms underlying inhibition of hypoglossal motor neuron excitability by riluzole. J Neurophysiol 110:1047-1061. CrossRef Medline

Bennett DJ, Li Y, Siu M (2001a) Plateau potentials in sacrocaudal motoneurons of chronic spinal rats, recorded in vitro. J Neurophysiol 86:19551971. Medline

Bennett DJ, Li Y, Harvey PJ, Gorassini M (2001b) Evidence for plateau potentials in tail motoneurons of awake chronic spinal rats with spasticity. J Neurophysiol 86:1972-1982. Medline

Bories C, Amendola J, Lamotte d'Incamps B, Durand J (2007) Early electrophysiological abnormalities in lumbar motoneurons in a transgenic mouse model of amyotrophic lateral sclerosis. Eur J Neurosci 25:451459. CrossRef Medline

Brooks BR (1996) Natural history of ALS: symptoms, strength, pulmonary function, and disability. Neurology 47:S71-81; discussion S81-82. CrossRef Medline

Bruijn LI, Miller TM, Cleveland DW (2004) Unraveling the mechanisms involved in motor neuron degeneration in ALS. Annu Rev Neurosci 27: 723-749. CrossRef Medline

Burke RE (1981) Motor units: anatomy, physiology and functional organization. In: Handbook of physiology: the nervous system, motor control, pp 877-994. Bethesda, MD: American Physiological Society.

Button DC, Gardiner K, Marqueste T, Gardiner PF (2006) Frequencycurrent relationships of rat hindlimb alpha-motoneurones. J Physiol 573: 663-677. CrossRef Medline

Carrascal L, Nieto-Gonzalez JL, Cameron WE, Torres B, Nunez-Abades PA (2005) Changes during the postnatal development in physiological and anatomical characteristics of rat motoneurons studied in vitro. Brain Res Rev 49:377-387. CrossRef Medline

Carrascal L, Nieto-Gonzalez JL, Núñez-Abades P, Torres B (2006) Temporal sequence of changes of electrophysiological properties of oculomotor neurons during postnatal development. Neuroscience 140:1223-1237. CrossRef Medline

Chandler SH, Hsaio CF, Inoue T, Goldberg LJ (1994) Electrophysiological properties of guinea pig trigeminal motoneurons recorded in vitro. J Neurophysiol 71:129-145. Medline

Cotel F, Antri M, Barthe JY, Orsal D (2009) Identified ankle extensor and flexor motoneurons display different firing profiles in the neonatal rat. J Neurosci 29:2748-2753. CrossRef Medline

Del Negro CA, Chandler SH (1998) Regulation of intrinsic and synaptic properties of neonatal rat trigeminal motoneurons by metabotropic glutamate receptors. J Neurosci 18:9216-9226. Medline

del Negro CA, Hsiao CF, Chandler SH (1999) Outward currents influencing bursting dynamics in guinea pig trigeminal motoneurons. J Neurophysiol 81:1478-1485. Medline

Delestrée N, Manuel M, Iglesias C, Elbasiouny SM, Heckman CJ, Zytnicki D (2014) Adult motoneurons are not hyperexcitable in a mouse model of inherited amyotrophic lateral sclerosis. J Physiol 592:1687-1703. CrossRef Medline

Durand J, Amendola J, Bories C, Lamotte d'Incamps B (2006) Early abnormalities in transgenic mouse models of amyotrophic lateral sclerosis. J Physiol Paris 99:211-220. CrossRef Medline

Elbasiouny SM, Amendola J, Durand J, Heckman CJ (2010) Evidence from computer simulations for alterations in the membrane biophysical properties and dendritic processing of synaptic inputs in mutant superoxide dismutase-1 motoneurons. J Neurosci 30:5544-5558. CrossRef Medline

Enoka RM, Pearson KG (2013) The motor unit and muscle action. In: Principles of neural science, Ed 5 (Kandel ER, Schwartz JH, Jessell TM, Seigelbaum SA, Hudspeth AJ, eds), pp 768-788. New York: McGraw-Hill.

Ferrucci M, Spalloni A, Bartalucci A, Cantafora E, Fulceri F, Nutini M, Longone P, Paparelli A, Fornai F (2010) A systematic study of brainstem motor nuclei in a mouse model of ALS, the effects of lithium. Neurobiol Dis 37:370-383. CrossRef Medline

Fleshman JW, Munson JB, Sypert GW, Friedman WA (1981) Rheobase, input resistance, and motor-unit type in medial gastrocnemius motoneurons in the cat. J Neurophysiol 46:1326-1338. Medline

Gardiner PF (1993) Physiological properties of motoneurons innervating different muscle unit types in rat gastrocnemius. J Neurophysiol 69:1160 1170. Medline

Gojo K, Abe S, Ide Y (2002) Characteristics of myofibres in the masseter muscle of mice during postnatal growth period. Anat Histol Embryol 31:105-112. CrossRef Medline

Gordon T, Tyreman N, Li S, Putman CT, Hegedus J (2010) Functional overload saves motor units in the SOD1-G93A transgenic mouse model of amyotrophic lateral sclerosis. Neurobiol Dis 37:412-422. CrossRef Medline

Granit R, Kernell D, Lamarre Y (1966) Algebraical summation in synaptic activation of motoneurones firing within the "primary range" to injected currents. J Physiol 187:379-399. Medline

Grosskreutz J, Van Den Bosch L, Keller BU (2010) Calcium dysregulation in amyotrophic lateral sclerosis. Cell Calcium 47:165-174. CrossRef Medline

Gupta A, Elgammal FS, Proddutur A, Shah S, Santhakumar V (2012) Decrease in tonic inhibition contributes to increase in dentate semilunar granule cell excitability after brain injury. J Neurosci 32:2523-2537. CrossRef Medline

Gurney ME, Pu H, Chiu AY, Dal Canto MC, Polchow CY, Alexander DD, Caliendo J, Hentati A, Kwon YW, Deng HX, et al. (1994) Motor neuron degeneration in mice that express a human $\mathrm{Cu}, \mathrm{Zn}$ superoxide dismutase mutation. Science 264:1772-1775. CrossRef Medline

Heckman CJ, Binder MD (1991) Computer simulation of the steady-state input-output function of the cat medial gastrocnemius motoneuron pool. J Neurophysiol 65:952-967. Medline

Hegedus J, Putman CT, Gordon T (2007) Time course of preferential motor unit loss in the SOD1 G93A mouse model of amyotrophic lateral sclerosis. Neurobiol Dis 28:154-164. CrossRef Medline

Hegedus J, Putman CT, Tyreman N, Gordon T (2008) Preferential motor unit loss in the SOD1 G93A transgenic mouse model of amyotrophic lateral sclerosis. J Physiol 586:3337-3351. CrossRef Medline

Hiiemae K (1971) The structure and function of the jaw muscles in the rat: II. Fibre type and composition. Zool J Linn 50:101-109. CrossRef

Kanning KC, Kaplan A, Henderson CE (2010) Motor neuron diversity in development and disease. Ann Rev Neurosci 33:409-440. CrossRef Medline

Kernell D (1966) Input resistance, electrical excitability, and size of ventral horn cells in cat spinal cord. Science 152:1637-1640. CrossRef Medline

Kernell D (1979) Rhythmic properties of motoneurones innervating muscle fibres of different speed in $\mathrm{m}$. gastrocnemius medialis of the cat. Brain Res 160:159-162. CrossRef Medline

Kernell D, Eerbeek O, Verhey BA (1983) Relation between isometric force and stimulus rate in cat's hindlimb motor units of different twitch contraction time. Exp Brain Res 50:220-227. Medline

Kuo JJ, Schonewille M, Siddique T, Schults AN, Fu R, Bär PR, Anelli R, Heckman CJ, Kroese AB (2004) Hyperexcitability of cultured spinal motoneurons from presymptomatic ALS mice. J Neurophysiol 91:571575. CrossRef Medline

Kuo JJ, Siddique T, Fu R, Heckman CJ (2005) Increased persistent $\mathrm{Na}(+)$ current and its effect on excitability in motoneurones cultured from mutant SOD1 mice. J Physiol 563:843-854. CrossRef Medline

Li Y, Bennett DJ (2003) Persistent sodium and calcium currents cause plateau potentials in motoneurons of chronic spinal rats. J Neurophysiol 90:857-869. CrossRef Medline

Li Y, Gorassini MA, Bennett DJ (2004) Role of persistent sodium and calcium currents in motoneuron firing and spasticity in chronic spinal rats. J Neurophysiol 91:767-783. CrossRef Medline

Limwongse V, DeSantis M (1977) Cell body locations and axonal pathways of neurons innervating muscles of mastication in the rat. Am J Anat 149:477-488. CrossRef Medline

Martin E, Cazenave W, Cattaert D, Branchereau P (2013) Embryonic alteration of motoneuron morphology induces hyperexcitability in the mouse model of amyotrophic lateral sclerosis. Neurobiol Dis 54:116-126. CrossRef Medline

Matsuda K, Uemura M, Kume M, Matsushima R, Mizuno N (1978) Topographical representation of masticatory muscles in the motor trigeminal nucleus in the rabbit: a HRP study. Neurosci Lett 8:1-4. CrossRef Medline 
Mizuno N, Konishi A, Sato M (1975) Localization of masticatory motoneurons in the cat and rat by means of retrograde axonal transport of horseradish peroxidase. J Comp Neurol 164:105-115. CrossRef Medline

Niessen HG, Angenstein F, Sander K, Kunz WS, Teuchert M, Ludolph AC, Heinze HJ, Scheich H, Vielhaber S (2006) In vivo quantification of spinal and bulbar motor neuron degeneration in the G93A-SOD1 transgenic mouse model of ALS by T2 relaxation time and apparent diffusion coefficient. Exp Neurol 201:293-300. CrossRef Medline

Nimchinsky EA, Young WG, Yeung G, Shah RA, Gordon JW, Bloom FE, Morrison JH, Hof PR (2000) Differential vulnerability of oculomotor, facial, and hypoglossal nuclei in G86R superoxide dismutase transgenic mice. J Comp Neurol 416:112-125. CrossRef Medline

Núñez-Abades PA, Spielmann JM, Barrionuevo G, Cameron WE (1993) In vitro electrophysiology of developing genioglossal motoneuronsin the rat. J Neurophysiol 70:1401-1411. Medline

Pieri M, Albo F, Gaetti C, Spalloni A, Bengtson CP, Longone P, Cavalcanti S, Zona C (2003) Altered excitability of motor neurons in a transgenic mouse model of familial amyotrophic lateral sclerosis. Neurosci Lett 351: 153-156. CrossRef Medline

Pun S, Santos AF, Saxena S, Xu L, Caroni P (2006) Selective vulnerability and pruning of phasic motoneuron axons in motoneuron disease alleviated by CNTF. Nat Neurosci 9:408-419. CrossRef Medline

Quinlan KA, Schuster JE, Fu R, Siddique T, Heckman CJ (2011) Altered postnatal maturation of electrical properties in spinal motoneurons in a mouse model of amyotrophic lateral sclerosis. J Physiol 589:2245-2260. CrossRef Medline

Radcliffe CB, Lockhart Clarke J (1862) An important case of paralysis and muscular atrophy with disease of the nervous centers. Br Foreign Med Chir Rev 30.

Saxena S, Roselli F, Singh K, Leptien K, Julien JP, Gros-Louis F, Caroni P (2013) Neuroprotection through excitability and mTOR required in ALS motoneurons to delay disease and extend survival. Neuron 80:80-96. CrossRef Medline

Schurr A, West CA, Rigor BM (1988) Lactate-supported synaptic function in the rat hippocampal slice preparation. Science 240:1326-1328. CrossRef Medline

Sessle BJ (1977) Identification of alpha and gamma trigeminal motoneurons and effects of stimulation of amygdala, cerebellum, and cerebral cortex. Exp Neurol 54:303-322. CrossRef Medline

Taylor A, Cody FW, Bosley MA (1973) Histochemical and mechanical properties of the jaw muscles of the cat. Exp Neurol 38:99-109. CrossRef Medline

Trueblood PR, Levine MS, Chandler SH (1996) Dual-component excitatory amino acid-mediated responses in trigeminal motoneurons and their modulation by serotonin in vitro. J Neurophysiol 76:2461-2473. Medline

Turkawski SJ, van Eijden TM (2000) EMG power spectrum and motor unit characteristics in the masseter muscle of the rabbit. J Dent Res 79:950956. CrossRef Medline

Turkin VV, O’Neill D, Jung R, Iarkov A, Hamm TM (2010) Characteristics and organization of discharge properties in rat hindlimb motoneurons. J Neurophysiol 104:1549-1565. CrossRef Medline

Uemura-Sumi M, Takahashi O, Matsushima R, Takata M, Yasui Y, Mizuno N (1982) Localization of masticatory motoneurons in the trigeminal motor nucleus of the guinea pig. Neurosci Lett 29:219-224. CrossRef Medline

van Eijden TM, Turkawski SJ (2002) Action potentials and twitch forces of rabbit masseter motor units at optimum jaw angle. Arch Oral Biol 47: 607-612. CrossRef Medline

van Zundert B, Peuscher MH, Hynynen M, Chen A, Neve RL, Brown RH Jr, Constantine-Paton M, Bellingham MC (2008) Neonatal neuronal circuitry shows hyperexcitable disturbance in a mouse model of the adultonset neurodegenerative disease amyotrophic lateral sclerosis. J Neurosci 28:10864-10874. CrossRef Medline

van Zundert B, Izaurieta P, Fritz E, Alvarez FJ (2012) Early pathogenesis in the adult-onset neurodegenerative disease amyotrophic lateral sclerosis. J Cell Biochem 113:3301-3312. CrossRef Medline

Venugopal S, Chandler SH (2012) Early evidence for disruption of cellular homeostasis in a mouse model for neurodegenerative motoneuron disease. In: Annual Society for Neuroscience Meeting: New Orleans, LA.

Vucic S, Kiernan MC (2006) Axonal excitability properties in amyotrophic lateral sclerosis. Clin Neurophysiol 117:1458-1466. CrossRef Medline

Wainger BJ, Kiskinis E, Mellin C, Wiskow O, Han SS, Sandoe J, Perez NP, Williams LA, Lee S, Boulting G, Berry JD, Brown RH Jr, Cudkowicz ME, Bean BP, Eggan K, Woolf CJ (2014) Intrinsic membrane hyperexcitability of amyotrophic lateral sclerosis patient-derived motor neurons. Cell Reports 7:1-11. CrossRef Medline

Zengel JE, Reid SA, Sypert GW, Munson JB (1985) Membrane electrical properties and prediction of motor-unit type of medial gastrocnemius motoneurons in the cat. J Neurophysiol 53:1323-1344. Medline 